\title{
Modelling drivers of mangrove propagule dispersal and restoration of abandoned shrimp farms
}

\author{
D. Di Nitto ${ }^{1}$, P. L. A. Erftemeijer ${ }^{2,3}$, J. K. L. van Beek ${ }^{4}$, F. Dahdouh-Guebas ${ }^{1,5}$, L. Higazi ${ }^{1}$, K. Quisthoudt ${ }^{1}$, \\ L. P. Jayatissa ${ }^{6}$, and N. Koedam ${ }^{1}$ \\ ${ }^{1}$ Biocomplexity Research Focus c/o Laboratory of Plant Biology and Nature Management, Mangrove Management Group, \\ Vrije Universiteit Brussel - VUB, Pleinlaan 2, 1050 Brussels, Belgium \\ ${ }^{2}$ Sinclair Knight Merz (SKM), P.O. Box H615, Perth WA 6001, Australia \\ ${ }^{3}$ The UWA Oceans Institute, University of Western Australia, 35 Stirling Highway, Crawley WA 6009, Australia \\ ${ }^{4}$ DELTARES (formerly Delft Hydraulics), P.O. Box 177, $2600 \mathrm{MH}$ Delft, the Netherlands \\ ${ }^{5}$ Laboratoire d'Écologie des Systèmes et Gestion des Ressources, Département de Biologie des Organismes, Faculté des \\ Sciences, Université Libre de Bruxelles - ULB, Campus de la Plaine, Avenue F.D. Roosevelt 50, CPI 264/1, 1050 Brussels, \\ Belgium \\ ${ }^{6}$ Department of Botany, University of Ruhuna, Matara, Sri Lanka
}

Correspondence to: D. Di Nitto (diana.dinitto@gmail.com)

Received: 21 December 2012 - Published in Biogeosciences Discuss.: 28 January 2013

Revised: 4 June 2013 - Accepted: 5 June 2013 - Published: 26 July 2013

\begin{abstract}
Propagule dispersal of four mangrove species $R h i$ zophora mucronata, $R$. apiculata, Ceriops tagal and Avicennia officinalis in the Pambala-Chilaw Lagoon Complex (Sri Lanka) was studied by combining a hydrodynamic model with species-specific knowledge on propagule dispersal behaviour. Propagule transport was simulated using a finitevolume advection-diffusion model to investigate the effect of dispersal vectors (tidal flow, freshwater discharge and wind), trapping agents (retention by vegetation) and seed characteristics (buoyancy) on propagule dispersal patterns. Sensitivity analysis showed that smaller propagules, like the ovalshaped propagules of Avicennia officinalis, dispersed over larger distances and were most sensitive to changing values of retention by mangrove vegetation compared to larger, torpedo-shaped propagules of Rhizophora spp. and C. tagal. Directional propagule dispersal in this semi-enclosed lagoon with a small tidal range was strongly concentrated towards the edges of the lagoon and channels. Short distance dispersal appeared to be the main dispersal strategy for all four studied species, with most of the propagules being retained within the vegetation. Only a small proportion (max. 5\%) of propagules left the lagoon through a channel connecting the lagoon with the open sea. Wind significantly influenced dispersal distance and direction once propagules entered the
\end{abstract}

lagoon or adjacent channels. Implications of these findings for mangrove restoration were tested by simulating partial removal in the model of dikes around abandoned shrimp ponds to restore tidal hydrology and facilitate natural recolonisation by mangroves. The specific location of dike removal, (with respect to the vicinity of mangroves and independently suitable hydrodynamic flows), was found to significantly affect the resultant quantities and species of inflowing propagules and hence the potential effectiveness of natural regeneration. These results demonstrate the value of propagule dispersal modelling in guiding hydrological restoration efforts that aim to facilitate natural mangrove regeneration.

\section{Introduction}

World aquaculture production continues to grow rapidly. Mainly in Asia and Latin America, shrimp farming has emerged as a major source of employment and income for many people (Naylor et al., 2000; Rönnbäck et al., 2002). However, when unregulated, these expanding economical activities can have major negative environmental and social impacts (Patil and Krishan, 1997; Ronnbäck, 2001; Rönnbäck et al., 2002). Over the years, many aquaculture ponds have 
been abandoned as it appeared that insufficient attention was paid to appropriate site selection, sustainable farm design and effective regulatory and institutional support (FAO, 2002; Lewis III et al., 2002). The conversion of mangrove ecosystems into brackish aquaculture ponds has occurred in many countries which all had significant mangrove resources (Dahdouh-Guebas et al., 2002b; Foell et al., 1999; Lewis III et al., 2002). Paradoxically, sustainability and productivity of fish and shrimp aquaculture is often strongly dependent on the provision of mangrove goods (e.g. fry and broodstock) as well as services (e.g. erosion control and water quality maintenance) (Beveridge et al., 1997; Kautsky et al., 2000; Rönnbäck, 1999; Rönnbäck et al., 2003).

To date there has been little coordinated research effort into pond restoration or rehabilitation (Primavera, 1993; Primavera et al., 2012a; Stevenson et al., 1999). Basically there are three options: (1) rehabilitation of the pond sites into sustainable shrimp production, (2) rehabilitation into an alternative, sustainable use or (3) restoration of the environmental conditions within these ponds and the surrounding area to re-establish a productive wetland ecosystem (Bosire et al., 2008; Lewis III et al., 2006; Lewis III, 2005; Stevenson and Burbridge, 1997; Stevenson, et al., 1999). Mangroves in disused pond areas can be restored since it has been reported that they can self-repair or successfully undergo secondary succession over periods of 15-30 yr (Primavera et al., 2012a, b; Stevenson et al., 1999). Regarding pond restoration, it is important to first restore the normal tidal flooding regime that is typically disrupted by existing farm infrastructure. Secondly, the availability of propagules or seedlings from adjacent mangrove stands is crucial for successful natural regeneration within these ponds. Only when natural recovery is not initiated after alleviating the latter potential disturbances, should actual planting of propagules, collected seeds or cultivated seedlings be envisaged (Bosire et al., 2008; Lewis III and Marshall, 1998; Lewis et al., 2006; Lewis III, 2005). Furthermore, the understanding of mangrove autoecology, more specifically the patterns of reproduction, propagule distribution and establishment, as well as the human-mangrove relationships, is vital within the design and implementation of any successful mangrove restoration project (Bosire et al., 2008; Lewis III and Marshall, 1998; Lewis III, 2005; Primavera, 1993, 1991, 1998; Primavera et al., 2012a, b; Stevenson et al., 1999). In addition, monitoring the success of restoration is an essential step in each restoration project in order to understand floristic succession, faunistic recruitment, environmental factors and so forth (Bosire et al., 2008; Primavera, 1993, 1991, 1998; Primavera, et al., 2012a, b). Nonetheless, mangrove restoration remains a complex matter. In the absence of studies quantifying the environmental conditions of disused ponds, there has been some debate on their re-use potential. The excavation and construction of shrimp ponds leads to soil oxidation, transforming the "potential acid sulphate soils" of a natural mangrove area into actual acid sul- phate soils (Lewis III et al., 2003; Stevenson and Burbridge, 1997; Stevenson et al., 1999).

Although soil recovery is possible to some extent, it is not known to what degree moderately acid sulphate soils limit mangrove recolonisation. Ecological restoration of mangroves, including the monitoring of mangrove hydrology and propagule availability, received little attention until recent years (Lewis III, 1999, 2005; Lewis III and Marshall, 1998; Lewis et al., 2006; Primavera, 1993; Primavera et al., 2012a, b). Implementing an ecological engineering project to restore mangroves is however not as simple as just breaching some dikes.

In Sri Lanka, poor water quality and poor site selection are amongst some of the main causes of large scale aquaculture production failure (Jayasinghe, 1995). According to estimates by the Ministry of Fisheries of the Northwestern Province, more than 1200 ha of mangroves have been totally destroyed for the purpose of shrimp farming (De Silva and Jacobson, 1995). Although natural mangrove regeneration has occurred within some abandoned aquaculture ponds in the Pambala-Chilaw Lagoon Complex, most ponds remain uncolonised even after several years of abandonment (Quisthoudt, 2007). The necessity of mangrove regrowth in abandoned ponds on the seaward side is urgent. In Sri Lanka, preliminary post-tsunami surveys of Sri Lankan mangrove sites with different degrees of degradation indicated that human activity exacerbated the damage inflicted on the coastal zone by the tsunami (Dahdouh-Guebas et al., 2005). In other words, mangroves were shown to function as protective buffers to shield coastal villages from destruction. Mangrove sites with no cryptic ecological degradation, or those well protected by distance inland and by Rhizophora spp. fringes, all experienced a low destructive impact from the tsunami. Although this study was conducted under posttsunami conditions, the same conclusions are relevant to a wide variety of extreme weather events and natural catastrophes, as the typhoons that frequently afflict the coastlines worldwide (Alongi, 2008; Gilman et al., 2008; Walters, 2003, 2004; Woodroffe and Grime, 1999).

In this study we focus on mangrove propagule dispersal within its ecological context and more specifically in view of shrimp pond restoration projects. How can speciesspecific propagule dispersal help understand a wider framework of mangrove vegetation structure dynamics, especially when considering long distance dispersal versus short distance dispersal? As the first aim of this study, a numerical model was constructed to simulate and study the effect of dispersal vectors (tidal flow, freshwater discharge, wind), trapping agents (retention by vegetation) and seed characteristics (buoyancy) on propagule distribution in the Pambala-Chilaw Lagoon Complex (Sri Lanka). The second aim of this study focused on the applicability of this model in view of mangrove restoration in abandoned shrimp farm areas. By modelling propagule dispersal, we examined to what extent the removal of certain parts of outer pond 
dikes could ensure sufficient propagule inflow from adjacent mangroves and consequently allow for natural regeneration. Propagule dispersal of 4 mangrove species Rhizophora mucronata Lamk., Rhizophora apiculata BL., Ceriops tagal (Perr.) C. B. Robinson and Avicennia officinalis L. was simulated through a combination of hydrodynamic modelling and species-specific dispersal modelling based on field data. This pioneer study is the first modelling exercise to date that applies such a combined bio-physical modelling set-up to simulate mangrove propagule dispersal. As many pioneer studies are not holistic, we acknowledge the reductionistic edge of this study regarding settlement processes and the effect of wave action on propagule dispersal. Yet, we think it is timely to explore possible propagule behaviour based on a substantial amount of field data against the backdrop of often repeated but little tested views on mangrove dispersal ecology.

\section{Materials and methods}

For the present study, a model was developed to simulate the transport by hydrodynamic flows of hydrochorous mangrove propagules with certain characteristics (shape, buoyancy) from the moment they are detached from their parental tree to their subsequent dispersal throughout the PambalaChilaw Lagoon Complex in Sri Lanka. The general methodology was derived from experiences gained in the two modelling studies on the dispersal of eelgrass seeds (2008) and fish larvae (2009). This combined bio-physical model setup was performed by means of the Delft3D-modelling suite which contains several interacting modules to simulate flows, waves, sediment transport, water quality, morphological developments and ecology (Lesser et al., 2004; Roelvink and Van Banning, 1994). As this approach is new within the discipline of mangrove ecology, we provide an elaborated overview of the methodology below (Fig. 2).

\subsection{Study area}

The Pambala-Chilaw Lagoon Complex (Fig. 1) is situated along the west coast of Sri Lanka, near the small town 'Chilaw' $\left(07^{\circ} 35^{\prime} 48^{\prime \prime} \mathrm{N}, 079^{\circ} 47^{\prime} 25^{\prime \prime} \mathrm{E}\right)$ and within the island's intermediate climate zone (Mueller-Dombois, 1968). The study area is about $17 \mathrm{~km}$ long and $4.5 \mathrm{~km}$ wide and is surrounded by mangrove forests and shrimp farms, many of which are currently abandoned. Flooding of these mangrove areas mainly occurs due to the heavy rainfalls during wet seasons; the micro-tidal regime limits the tidal range to $\ll 1 \mathrm{~m}$. Chilaw Lagoon is an intermittently closed tidal lagoon with a connection to open ocean through a narrow and long channel (Dutch Canal), which is joined at the most northern and southern ends of the lagoon. These entrances are temporarily open or closed depending on local sandbar formation and movement, which varies seasonally and between years (Baranasuriya, 2001). The northern entrance may be closed incidentally (usually during dry summers), while the southern entrance (Thoduwawa) is closed throughout most of the year. However, due to local economic activities, both entrances are periodically dredged to allow boat traffic and to avoid floods upstream.

There are no rivers discharging directly into Chilaw Lagoon (Fig. 1). Most freshwater influx stems from the Karabalan Oya catchment (and possibly Deduru Oya) and rainwater runoff channels discharging at regular intervals. The Karabalan Oya and the Dedura Oya have catchment areas of $596 \mathrm{~km}^{2}$ and $2647 \mathrm{~km}^{2}$ and annual mean discharge in the order of $8 \mathrm{~m}^{3} \mathrm{~s}^{-1}$ and $36 \mathrm{~m}^{3} \mathrm{~s}^{-1}$ respectively (UNEP/GPA, 2003).

The mangrove forests within this area are typical fringe or riverine forests (Lugo and Snedaker, 1974) with an irregular distribution along a complex of creeks (Fig. 1). There are 16 mangrove species present in the lagoon (Jayatissa et al., 2002), of which Rhizophora mucronata, Rhizophora apiculata, Ceriops tagal and Avicennia officinalis are the most dominant in the study area. Shrimp farming has encroached into this area, expanding to 25 ha by 1998 in the Pambala region, mainly at the expense of mangrove forests (approx. $13 \mathrm{ha}$ ) and coconut plantations (approx. $11 \mathrm{ha}$ ) (DahdouhGuebas et al., 2002b). The location of mangrove areas and shrimp farms (active and non-active) around the lagoon is shown in Fig. 1. Weather patterns in Sri Lanka, in particular the seasonal rainfall variations, are determined by a monsoon regime and coincide with a major change in the wind field together with the southward and northward shift of the Intertropical Convergence Zone (Domroes and Ranatunge, 1992). The Northeast Monsoon (December to early March) is weaker and shorter-lived than the Southwest Monsoon (midMay to early October), which is reflected in the wind patterns respectively orientated from north to northeast and from west to south (Swan, 1983).

\subsection{Field measurements}

\subsubsection{Input field data for the hydrodynamic model}

Water level and salinity measurements were taken at several stations within the lagoon from 1 April 1998 until 29 June 1998. Time series of water levels and salinity variations were recorded respectively by means of Micro Tide pressure gauges from Coastal Leasing, USA with an absolute accuracy of $\pm 1.5 \mathrm{~cm}$ and an Aanderaa Environmental Monitoring System (EMS) of which the accuracy amounts to $\pm 0.1 \%$. The locations of the instruments (Fig. 1, white dots) were selected in order to specify model boundary conditions and to collect data for model calibration and validation at control points. Data were recorded at 10 min intervals. Additionally, in January-February 2007, daily salinity measurements were recorded at several points along the PambalaChilaw Lagoon Complex (Fig. 1, red dots). 

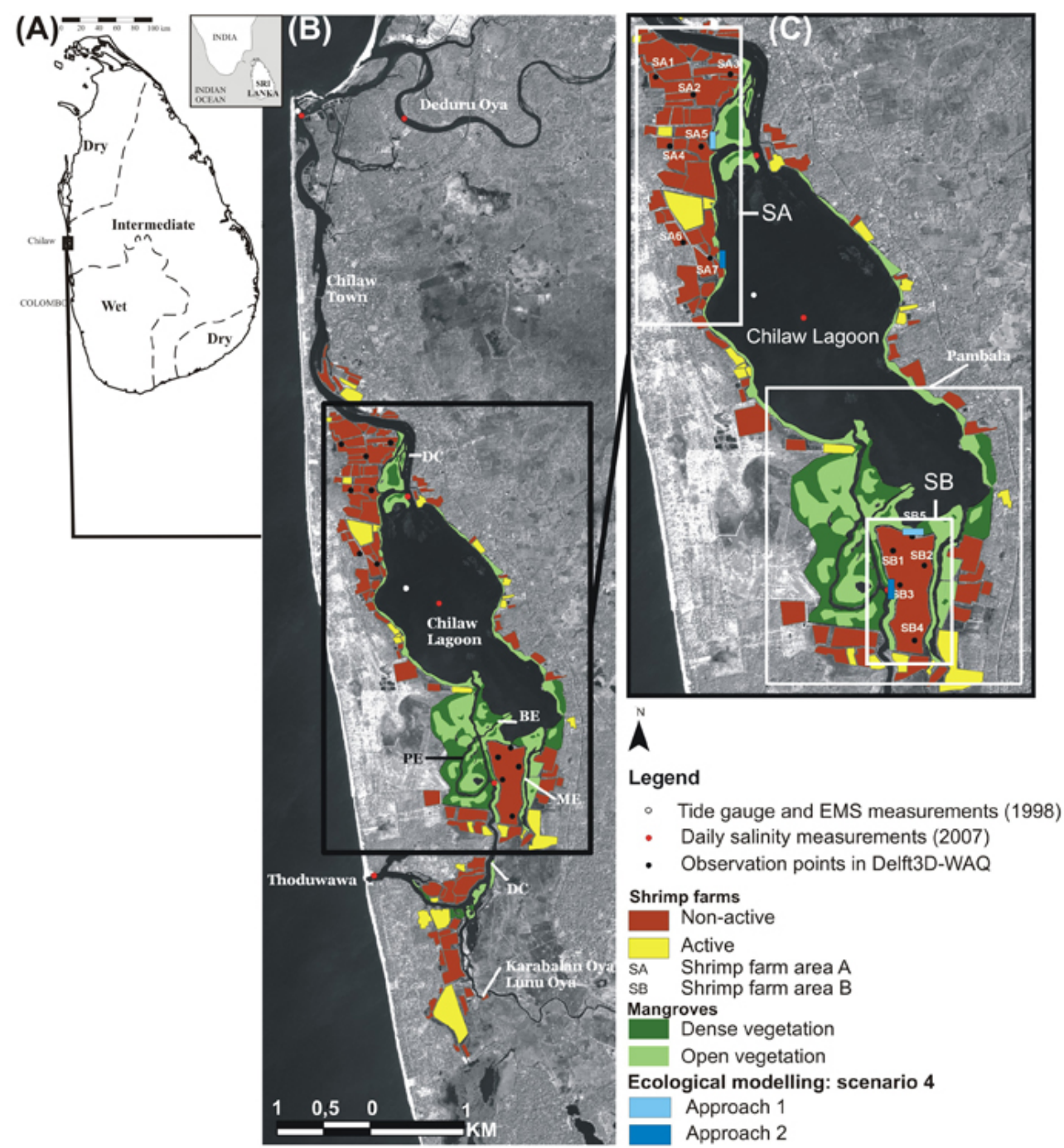

Fig. 1. (A) Representation of Sri Lanka (Dahdouh-Guebas et al., 2000), (B) an IKONOS image (2002) showing the Pambala-Chilaw Lagoon Complex, (C) Indication of the water level and salinity measurements points (both in 1998 and 2007), the observation points in Delft3DWAQ within shrimp farm area $\mathrm{A}$ and $\mathrm{B}$, the active and non-active shrimp farms, the dense and open mangrove vegetation and the channels. Locations of outer dike removal (approach 1 and 2) are also indicated. EMS = Environmental Monitoring System. DC = Dutch Canal, $\mathrm{PE}=$ Pol Ela, $\mathrm{ME}=$ Marambettiya Ela, $\mathrm{BE}=$ Bate Ela.

Bathymetry was measured in the field in JanuaryFebruary 2007. Depth values were recorded along line transects within the lagoon, channels and creeks by means of a hand-held echo sounder (deeper areas, $>0.6 \mathrm{~m}$ ) and by means of aluminium tower ruler divided into $0.5 \mathrm{~cm}$ intervals (shallower areas). These measurements were corrected for tides by subtracting the corresponding heights of the tide from the daily measurements.

Data concerning precipitation, wind speed and direction were obtained from the Meteorology Department in Colombo (Sri Lanka). Daily precipitation data $(\mathrm{mm})$ was available for the station in Puttalam for the period 1997-2006, while 3-hourly data regarding wind speed and direction were available from the Puttalam station for the period 2002-2007. Unfortunately, discharge measurements were not available, except (as stated above) for annual measurements of the total annual freshwater influx derived from the Irrigation Department in Sri Lanka (UNEP/GPA, 2003).

\subsubsection{Input field data for the propagule dispersal model}

Experiments on propagule buoyancy were conducted in situ during January-February 2007. Propagules of Rhizophora mucronata, $R$. apiculata, Ceriops tagal and Avicennia officinalis were collected in the field by either shaking the branches from a mangrove tree or by picking mature propagules from the tree based on the colour of the cotyledons and the "ease" by which they detach. These propagules were 


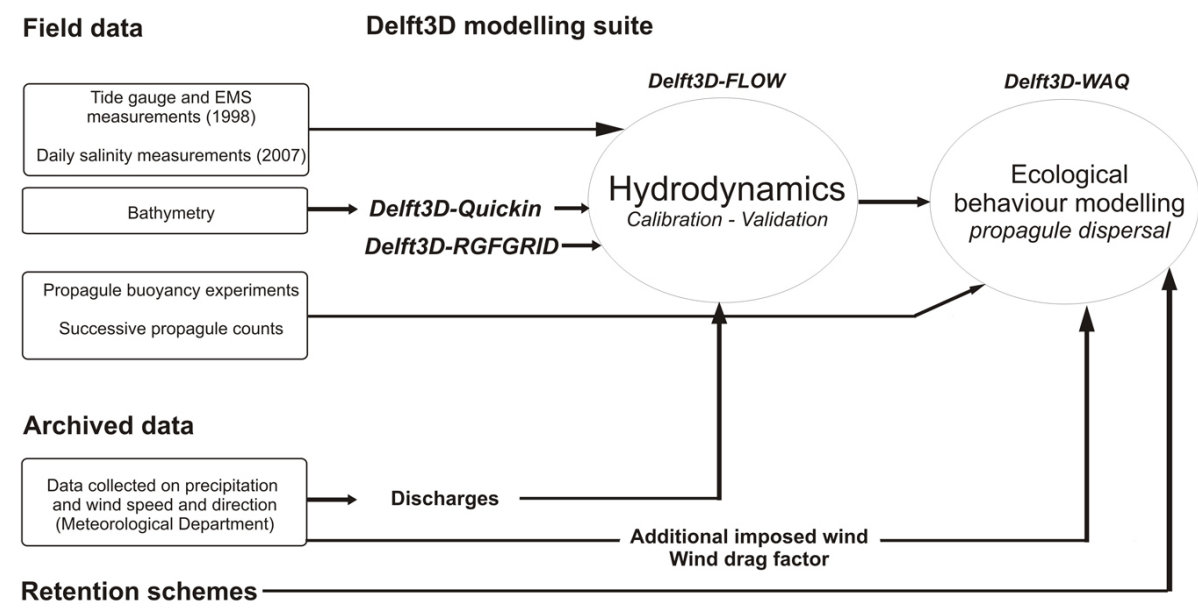

Fig. 2. Overview of the applied methodology.

placed in water basins with different salinity values $(35,30$, $25,20,10,5$ and $0 \%$ o) and tested on their buoyancy during a time span of two weeks with a total of 14 sampling times. "Buoyancy" is here defined as "floating in the water, regardless of orientation and position within the water column", whereas "buoyancy period" is the period of time that this happens. In a microtidal mangrove area, large areas can remain unflooded for a substantial amount of time. This means that propagules can fall from their parental tree and lay on the mangrove floor to dry. The effect of drying (for 1,2 and 3 weeks) on propagule buoyancy of Rhizophora mucronata, $R$. apiculata and Ceriops tagal was also investigated (Higazi, 2008). In addition, every three days and for a period of three weeks, successive propagule counts were conducted within 38 permanent quadrats of $4 \mathrm{~m}^{2}$ in the mangrove forest near Pambala. These quadrats were chosen based on the environmental factors "slope", "top soil texture" and "root complex". For each quadrat, the number of propagules on the forest floor was recorded and the percentage coverage of the adult trees visually estimated (Higazi, 2008). These values will be used as input values for the number of propagules released at different locations within the advection-diffusion model (see Table 2).

\subsection{Hydrodynamic model}

The hydrodynamic model was constructed by means of Delft3D-FLOW. Three-dimensional unsteady flow and transport phenomena resulting from tidal and meteorological forcing were simulated by solving well-established shallowwater hydrodynamic equations (Lesser et al., 2004; Stelling, 1983). The model equations, formulated in orthogonal curvilinear coordinates, were discretised onto a staggered Arakawa-C grid and time-integrated by means of an ADI (Alternating Direction Implicit) numerical scheme in horizontal directions and by Crank-Nicolson along the vertical. The latter was discretised by terrain following coordi- nates through $\sigma$-transformation (Leendertse, 1987; Stelling, 1983). This code was extended on the one hand with transport of salt and heat content and on the other hand with the k- $\varepsilon$ model (Launder and Spalding, 1982) for vertical exchange of horizontal momentum and matter or heat, possibly subjected to density stratification. Along the open (sea) boundaries, constituents from tidal harmonics of water level patterns were imposed. The solution of this modelling process was mass conserving at every grid cell and time step ( $2 \mathrm{~min}$ ) and coupled off-line to the advection-diffusion model Delft3D-WAQ. For the computation of the surface roughness, a Manning roughness coefficient, $n$, of $0.024 \mathrm{~s} \mathrm{~m}^{-1 / 3}$ was used as an input value for the calculation of the Chèzy friction coefficient, which is depth-dependent and therefore calculated each time step.

\subsubsection{Model grid resolution and bathymetry}

By means of Delft3D-RGFGRID, a model grid was developed consisting in total of 21111 computational elements and covering the whole study area. The horizontal dimension covered grid cells with a resolution in the order of 35 metres. The vertical dimension was represented by subdividing the water column into 5 layers, each representing $20 \%$ of the water depth, following a sigma-coordinated approach to ensure sufficient vertical resolution in the near-coastal zone (Stelling and Van Kester, 1994). Run time of the hydrodynamic model for a two months long simulation required approximately $5 \mathrm{~h}$.

The 5-layered coupled communication output files, generated every hour, were subsequently aggregated vertically to 1 layer and then used as input files for the advection-diffusion model to simulate the biological transport modelling of mangrove propagules (see below). Since the propagules spend most of the dispersal phase floating on the water surface, due to their buoyancy characteristics, and rapidly sink to the bottom at the end of their flotation period, aggregation 
to a 2-D model was considered acceptable for the purpose of this study. Test runs revealed that differences in dispersal patterns between vertically aggregated and multi-layered Delft3D-WAQ runs were negligible. Horizontal aggregation of grid resolution was not applied in any of the model runs.

For the generation and interpolation of the bathymetry, Delft3D-Quickin was used. A shapefile containing the horizontal $(X, Y)$ and vertical $(Z)$ coordinates of the measured depth points was generated in ArcGIS 8.3 (ESRI) and subsequently imported in Delft3D-Quickin as a sample file. All sample points were interpolated by triangulation, a method which is best suited for datasets with a resolution that is about equal to or smaller than the grid resolution. The sample points were first organised into a Delaunay network (Raper, 1990), after which grid values were interpolated.

\subsubsection{Model forcing}

The hydrodynamic model was forced using temporally varying meteorological data comprising of a horizontal wind velocity and direction component archived every $3 \mathrm{~h}$ from 2002-2007 at a station in Puttalam, situated north of the study area. For the two seasons, April-May 1998 (wet season) and July-August 2007 (dry season), modelled in Delft3D-FLOW, time series of wind velocity and direction were derived by averaging over the 5 consecutive years.

One discharge point was assigned at the junction of the Karabalan Oya with the southern part of the Dutch Canal, where salinity was assumed to be constant $(0 \%)$. Discharge rates were derived from scaling the total annual discharge according to averaged monthly precipitation values.

\subsubsection{Calibration and validation of hydrodynamics}

Calibration of the hydrodynamics was accomplished based on available water levels within the northern part of the Dutch Canal (Fig. 1) for the period 1 April 1998 until 29 Juni 1998. Several adjustments were made to the boundary conditions in order to obtain an optimal similarity between modelled and observed water level amplitudes and phases for a large number of tidal constituents, more specifically by altering the phase difference between the north and south boundary within the tidal constituents. Model validation was done by using salinity patterns recorded within the Chilaw Lagoon (Fig. 1) from 15 May 1998 until 29 June 1998. Goodness-of-fit between model results and field measurements were tested by means of two approaches: (1) $r^{2}$ (square of the correlation coefficient), and (2) biasn (normalised bias) calculated according to Jolliff et al. (2009) as follows:

$\operatorname{Bias} n=\operatorname{Bias} /(\sigma d)$

with Bias $=$ Mean $($ model $)-$ Mean (data) and $\sigma d=$ standard deviation of the data.

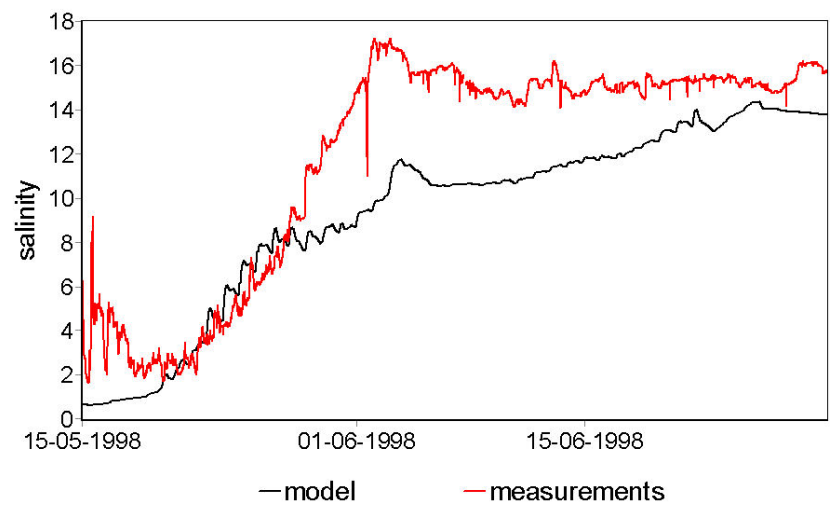

Fig. 3. Validation of the hydrodynamic model: presentation of the salinities measured in the field (red) versus the salinities generated by the model (black).

The $r^{2}$ (square of Pearson product-moment correlation coefficient) between the salinity measured in the field versus the salinity generated by the model was 0.85 meaning that the range and general trend of the datasets were good (Fig. 3). Biasn (normalised bias) was -0.51 which indicates that the model average deviated considerably from the field measurements. This was most likely due to the fact that accurate freshwater discharge data were not available for Chilaw Lagoon. However, the salinity values showed correspondence between model and field measurements throughout the simulated period, with highest and lowest values occurring in the same periods. As we do not intend to generate conclusions on absolute quantitative values of propagule dispersal, we consider the hydrodynamic model as acceptable for the purpose of the sensitivity analysis and relative interpretation of the propagule dispersal scenario modelling results.

\subsection{Advection-diffusion model}

Delft3D-WAQ, the water quality module of Delft3D, calculates the transport of substances by numerically solving the advection-diffusion reaction equation on a predefined computational grid and for a wide range of model substances (Postma, 1988). The Delft3D-WAQ model considers computational elements (or segments) as volumes that are linked to each other and where transport between segments are derived from dedicated models (e.g. simulated in Delft3D-FLOW). Internally, Delft3D-WAQ multiplies fluxes with concentrations to obtain masses for each time step across internal and external boundaries and includes a large selection of numerical solution schemes.

In order to simulate the propagule transport of different mangrove species, we used a generic advection-diffusion model that was originally developed to simulate the dispersal of eelgrass seeds via floating generative shoots (Erftemeijer et al., 2008). We have opted for the finite-volume method offered by Delft3D-WAQ, rather than a particle 
Table 1. Propagule dispersal characteristics of the species Ceriops tagal, Rhizophora mucronata, R. apiculata and Avicennia officinalis (e.g. Clarke, 1993; Clarke Peter et al., 2001; Drexler, 2001; Rabinowitz, 1978). S = salt water, F= fresh water, na = data not available.

\begin{tabular}{|c|c|c|c|c|}
\hline Species & Ceriops tagal & Rhizophora mucronata & Rhizophora apiculata & Avicennia officinalis \\
\hline Family & Rhizophoraceae & Rhizophoraceae & Rhizophoraceae & Acanthaceae \\
\hline Vivipary & Viviparous & Viviparous & Viviparous & Cryptoviviparous \\
\hline Propagule type & Seedling & Seedling & Seedling & Seedling \\
\hline Shape & Torpedo-shaped & Torpedo-shaped & Torpedo-shaped & Oval-shaped \\
\hline Dispersal part & Hypocotyl & Hypocotyl & Hypocotyl & Cotyledon \\
\hline $\begin{array}{l}\text { Mean fresh mass of propagules } \\
\text { (g) (SE) }\end{array}$ & $11.70(2.40)$ & $48.40(14.51)$ & $20.60(5.10)$ & $1.10(0.11)$ \\
\hline Mean length of propagules $(\mathrm{cm})$ & $30.00(3.50)$ & $39.90(6.62)$ & $24.20(2.80)$ & $1.83(0.05)$ \\
\hline $\begin{array}{l}\text { Predominant buoyancy pattern in } \\
\text { saltwater }\end{array}$ & Floater & Floater & Floater & Floater \\
\hline $\begin{array}{l}\text { Predominant buoyancy pattern in } \\
\text { freshwater }\end{array}$ & Floater & Floater & Floater & $\begin{array}{l}\text { Floater (after } \\
\text { initially sinking) }\end{array}$ \\
\hline Obligated dispersal & na & \pm 40 days & \pm 40 days & $7-21$ days \\
\hline $\begin{array}{l}\text { Time until root initiation (days), averaged } \\
\text { over all salinity treatments }\end{array}$ & Starting from \pm 14 days & $15-40$ days & $15-40$ days & $7-10$ days \\
\hline $\begin{array}{l}\% \text { of propagules with roots after } \\
23 \text { days (SE) }\end{array}$ & $8.3(3.3)$ & na & na & $100(0.00)$ \\
\hline Longevity (days) & na & 150 & 89 & 110 days $\mathrm{S}$ Longer $\mathrm{F}$ \\
\hline Flowering (Sri Lanka, Negombo) & Apr-Jun, Sept-Dec & Feb-Mar, Jun-Aug & Apr-Jun & Mar-Jul \\
\hline $\begin{array}{l}\text { Fruiting (falling of propagules) } \\
\text { (Sri Lanka, Negombo) }\end{array}$ & Jun-Aug, Dec & Jul-Aug & Jun-Oct & Apr-Sep \\
\hline
\end{tabular}

tracking method. While the latter method offers the possibility to follow particles as individuals and assign them specific properties, mangrove propagules are passive dispersal units assumed to react similarly. Since the process parameters mainly depend on their shape and buoyancy properties (orientation and position in the water column), this approach is sufficient for the purpose of this study, i.e. differentiate between species and to model the dispersal of different cohorts of propagules per species, each with their own buoyancy properties. When properly used, both finite-volume methods and particle tracking model approaches should provide comparable results (Zhang and Chen, 2007).

\subsubsection{Definition of processes and parameters}

When simulating propagule dispersal, species-specific knowledge on buoyancy duration, longevity, period required for establishment and obligated dispersal (time taken for viable, floating propagules to develop lateral roots) are very important. Propagule dispersal characteristics of four different mangrove species (Rhizophora mucronata, $R$. apiculata, Ceriops tagal and Avicennia officinalis) were obtained from published data and additional experiments by our group (Table 1). Buoyancy characteristics can change with varying salinities, and could influence propagule dispersal patterns in different seasonal periods with dissimilar discharge rates.

Retention and release of propagules within mangrove vegetation is another equally important parameter with respect to hydrochorous dispersal. Retention means that propagules can be retained within the vegetation for a certain period after which they can be released again to an adjacent vege- tation patch. The retention and release values implemented within this model were experimentally established and found to be different between species; smaller, oval-shaped propagules (like $A$. officinalis) having smaller retention values and higher release values than larger, torpedo-shaped propagules (like $R$. mucronata). Retention and release values were also dependent on the vegetation structure, varying from open to dense. Given the lack of published data on this complicated matter, different schemes of retention and release were applied varying from minimum and intermediate to maximum values. Finally, the effect of wind speed and direction on propagule dispersal by water currents was considered by applying a wind drag function (3\% of wind speed sensu Tsanis, 1989) on surface currents in the model.

Specific discharge points were assigned to release the propagule "concentrations" at 10 different places within the mangrove areas where their parental trees were known to be present. The amount of propagules released during one run by means of Delft3D-WAQ (Table 2) was based on the successive density of available propagules counted in the field within the permanent quadrats dominated by the concerned species ( $>50 \%$ of adult tree coverage). For each species, the average number of propagules at the beginning of the counts was listed as well as the average increase of propagules after a time span of three weeks.

\subsubsection{Sensitivity analysis and seasonal variability}

A sensitivity analysis was done to determine how "sensitive" the output of the model is to changes in parameter input values of the model, i.e. by varying the buoyancy period and the 
Table 2. Input values of propagule "concentrations" in Delft3D-WAQ based on the successive propagule counts. Given the nature of the advection-diffusion model, the input requires the numbers of propagules to be converted into concentrations $\left(\mathrm{g} \mathrm{m}^{-3}\right)$.

\begin{tabular}{lccc}
\hline Genera & Rhizophoza & Ceriops & Avicennia \\
\hline $\begin{array}{l}\text { Average number of propagules present at the } \\
\text { start of the propagule counts }\end{array}$ & 54 & 75 & 12 \\
$\begin{array}{l}\text { Concentration of propagules as initial input value } \\
\text { in WAQ }\left(\mathrm{g} \mathrm{m}^{-3} \text { per s, time step }=15 \mathrm{~min}\right)\end{array}$ & 0.0600 & 0.0833 & 0.0133 \\
$\begin{array}{l}\text { Average increase of the number of propagules } \\
\text { during the propagule counts }\end{array}$ & 60 & 61 & 14 \\
$\begin{array}{l}\text { Concentration of propagule increase as input value } \\
\text { in WAQ }\left(\mathrm{g} \mathrm{m}^{-3} \text { per s, time step }=15 \mathrm{~min}\right)\end{array}$ & 0.0667 & 0.0678 & 0.0156 \\
\hline
\end{tabular}

values of retention and release. Initial input values of propagule concentrations at the moment of release $\left(T_{0}\right)$ were kept constant for all species.

In addition, seasonal variability was analysed by modelling and comparing propagule dispersal within two seasons, the wet season and the dry season respectively from April to May and July to August. This was done for all scenarios (see below). We acknowledge the seasonal variability of propagule production (Table 1) (Kumara, 2001) and the fact that the assigned release points represent a realistic situation which is however more extensive if all spatiotemporal release points would be considered. Therefore, these results were interpreted only for a relative comparison between species.

\subsubsection{Scenarios}

The main objective of this study was to investigate the effect of dispersal vectors (tidal flow, freshwater discharge, wind), trapping agents (retention by vegetation) and seed characteristics (buoyancy) on propagule dispersal. In addition, we simulated the effect of dike removal on mangrove regeneration in abandoned shrimp farm areas.

\section{Scenario 1: What is the effect of species-specific buoyancy characteristics on propagule dispersal?}

The obligated dispersal period, which is the time that propagules remain viable and start developing lateral roots while floating, was modelled for the four different mangrove species, (i.e. Rhizophora mucronata, R. apiculata, Ceriops tagal and Avicennia officinalis) based on published data on their buoyancy properties.

\section{Scenario 2: What is the effect of drying of propagules on their dispersal?}

The dispersal of fresh propagules versus for 1 week, 2 weeks and 3 weeks dried propagules was modelled with the intention of examining the effect of drying-induced buoyancy changes on the dispersal extent of these propagules. The values regarding the buoyancy factor were based on the findings of the buoyancy field experiments, available for the species Rhizophora mucronata, R. apiculata and Ceriops tagal (Higazi, 2008).

\section{Scenario 3: What is the effect of wind on propagule dispersal?}

The effect of sporadic high wind velocities on maximum propagule dispersal extents was investigated for the species Rhizophora mucronata, R. apiculata, Ceriops tagal and Avicennia officinalis. Especially in large, open water bodies, like Chilaw Lagoon, high wind velocities can generate small waves in the upper layer of the water column which could strongly influence the dispersal of propagules. Within this scenario the effect of additional wind was included by implementing the maximum values per month derived from the 3-hourly data available from the Meteorological Department in Colombo, Sri Lanka. The effect of waves was not modelled.

\section{Scenario 4: What is the effect of dike removal (rehabilitation of shrimp pond areas) on propagule dispersal?}

Removal of parts of outer dikes of abandoned shrimp farms was simulated to assess to what extent this could assure the inflow of propagules from adjacent mangroves and facilitate natural regeneration. Observation points were added in the two main shrimp farm areas A (SA1-SA7) and B (SB1SB5) (Fig. 1). In approach 1, part $(60 \mathrm{~m})$ of an outer dike was removed at the northeastern side of shrimp farm $A$ and the northern side of shrimp farm B, while in approach 2 part $(60 \mathrm{~m})$ of the outer dike at the southeastern side of shrimp farm $\mathrm{A}$ and the northwestern side of shrimp farm B was removed. The locations of dike removal were chosen based on a preliminary assessment of potentially favourable hydrodynamic flows towards these abandoned shrimp farms. In addition to the selection of the most suitable locations to breach 
the outer dikes of abandoned shrimp pond areas, we emphasise the importance of the number of breaches (Lewis et al., 2006). Limiting the number of breaches is considered critical as the tidal prism (the amount of water that can enter an opened pond between high and low tide) needs to be channelled through a few key openings to mimic the normal operation of tidal streams in mangroves. Fewer openings produce greater velocities as the flow is restricted, which in turn produces "self"-scouring, keeping the man-made openings open and reducing the chances of siltation and closure (Lewis III et al., 2006). Sediment transport and related geomorphologic processes after dike removal were not considered.

\subsubsection{Analysis of model output}

Model output of the propagule dispersal modelling for the different scenarios was post-processed in two ways:

Distribution patterns: graphic contour plots of the temporal and spatial distribution of propagules (densities per $\mathrm{m}^{2}$ ).

Time series plots: propagule densities $\left(\mathrm{N} \mathrm{m}^{-2}\right.$, $N=$ number) at selected observation points, accumulated over time during the modelled time series.

\section{Results}

\subsection{Sensitivity analysis and seasonal variability}

Model results (wet season) for the four species indicated that smaller propagules, like the oval-shaped propagules of Avicennia officinalis, were the most sensitive to changing values of retention and release (Fig. 4a). The minimum retention scheme (in combination with high release values) signified a wide dispersal extent of $A$. officinalis along both the northern and the southern parts of the lagoon. The maximum retention scheme (in combination with low release values) limited the dispersal of this species to the southernmost part of the lagoon. These results indicate that propagules of $A$. officinalis released from the southern part of the lagoon might also be important for replenishing sites along the northern part if retention is low. Irrespective of the retention scheme, part of the propagules released from adult trees situated on the lagoon banks within the northern mangrove area, were lost from the lagoon system through the northern part of the Dutch Canal. A small portion of these propagules $(\max 5 \%$ ) had the ability to disperse along the northern mangrove area under the minimum retention scheme, while a maximum retention scheme prevented distribution of Avicennia into this part of the lagoon. Larger, torpedo-shaped propagules represented by the genus Rhizophora appeared to be less sensitive to changes in values of retention and release. All retention schemes (minimum, intermediate and maximum) restricted the dispersal extent of $R$. mucronata to the southernmost part of the lagoon (Fig. 4b). The latter was true for a varying buoyancy period of 1 week, 2 weeks and 4 weeks (results not shown).
Results for the dry season confirmed that A. officinalis remained the most sensitive species with respect to changes in retention and its effect on the propagule dispersal extent, while sensitivity to varying buoyancy periods was less significant for all species. While some dispersal of A. officinalis, $R$. mucronata and $R$. apiculata propagules occurred during the dry season, there was no significant spatial dispersal pattern for Ceriops tagal propagules in the model (data not shown). During dry seasons, flooding of the inner mangrove areas is rare, but genera that also occur along the lagoon and riverbanks, such as Avicennia and Rhizophora, can still disperse along water bodies without being retained within the inner mangrove vegetation. Inversely, species restricted to the northern mangrove areas and occupying a more landward position, such as $C$. tagal, are rarely inundated and therefore have no opportunity for any propagule dispersal during the dry season. Rhizophora apiculata and $R$. mucronata displayed dispersal patterns similar to A. officinalis, although less distinct in the dry season.

\subsection{Scenario 1: Effect of species-specific buoyancy characteristics on propagule dispersal}

The results of scenario 1 show that Avicennia officinalis had a more extensive propagule dispersal range in the dry season than in the wet season (Fig. 5). The minimum retention scheme of the dry season resulted in dispersal of its propagules along all parts of the lagoon as well as along all connecting channels. Differences in dispersal patterns of Rhizophora apiculata and $R$. mucronata between the wet season and the dry season were less pronounced in comparison to the dispersal patterns of A. officinalis. Ceriops tagal had no propagule dispersal during the dry season yet an extensive dispersal during the wet season under conditions of minimal retention.

\subsection{Scenario 2: Effect of drying of propagules on their dispersal}

Figure 6 shows the model output distribution plots for Rhizophora mucronata when comparing the propagule dispersal extent of fresh propagules versus propagules dried for 3 weeks. Field experiments revealed that (1) buoyancy differences mainly occurred when propagules were naturally dried for 3 weeks and (2) drying only affected Rhizophora species. Model results for the wet season indicated that the drying of propagules for 3 weeks of Rhizophora mucronata within the lagoon resulted in a more concentrated extent of dispersal near the release points (Fig. 6), while still allowing for some propagule distribution of $R$. mucronata throughout the southern part of Dutch Canal, Pol Ela and Marambettiya Ela. Similar results were obtained for $R$. apiculata (data not shown). The main difference in dispersal between fresh propagules and 3 weeks dried propagules (both species) was that a portion of the dried propagules released within the mangrove area north of the lagoon had not left the system along the 


\section{SENSITIVITY ANALYSIS}

Different schemes of retention, buoyancy period of 1 week

Avicennia officinalis

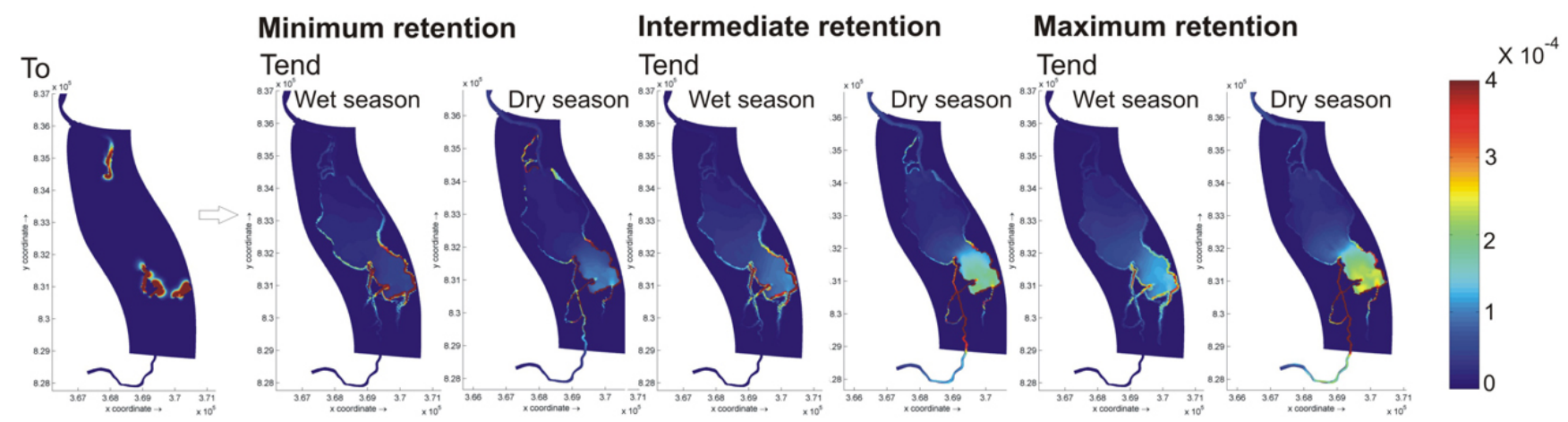

Fig. 4a. Results of the sensitivity analysis: distribution patterns for the species Avicennia officinalis when varying the retention schemes from minimum, intermediate to maximum retention values. Red, yellow and light blue colours indicate a high, medium and low concentration of propagules respectively.

\section{SENSITIVITY ANALYSIS}

Different schemes of retention, buoyancy period of 1 week

Rhizophora mucronata

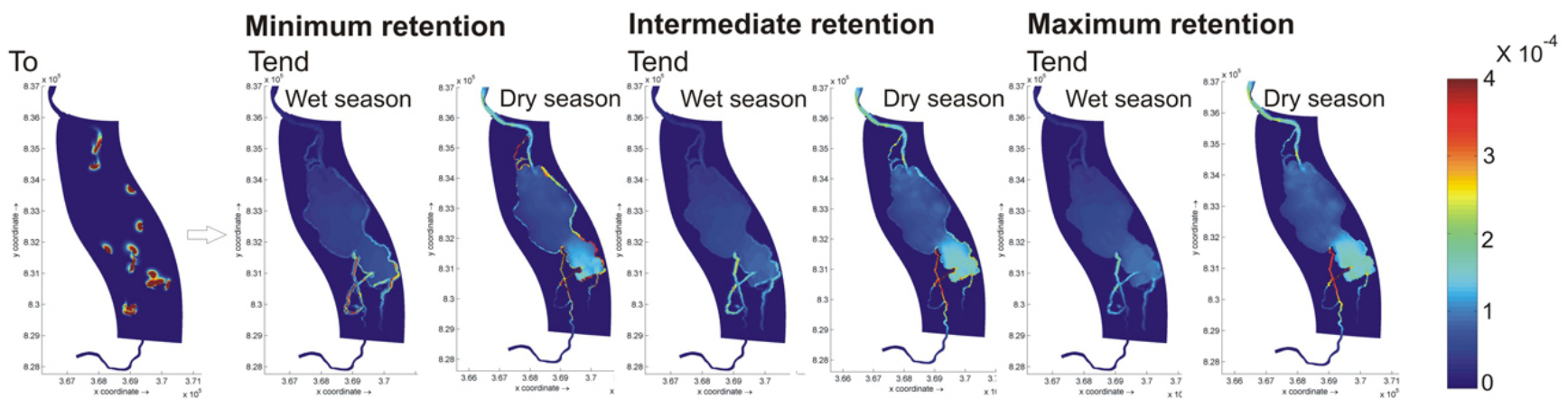

Fig. 4b. Results of the sensitivity analysis: distribution patterns for the species Rhizophora mucronata when varying the retention schemes from minimum, intermediate to maximum retention values. Red, yellow and light blue colours indicate a high, medium and low concentration of propagules respectively.

northern part of the Dutch Canal. During the dry season, propagule distribution was also concentrated near the release points (results not shown).

\subsection{Scenario 3: Effect of wind on propagule dispersal}

"Additional wind" (high velocities) had a significant effect on the dispersal of propagules (Fig. 7 for Rhizophora mucronata). Irrespective of the retention scheme, distribution patterns clearly indicated that with high wind velocities, propagules of Avicennia officinalis, Rhizophora apiculata and $R$. mucronata tend to disperse more to the southern part of the study area along the channel Marambettiya Ela. With respect to seasonal variation, distribution patterns were similar, however dispersal of propagules along the Marambettiya
Ela was less pronounced during the dry season. Only for $\mathrm{Ce}$ riops tagal differences between propagule dispersal patterns with or without the "additional" wind were negligible (results not shown).

\subsection{Scenario 4: Effect of dike removal for rehabilitation of shrimp pond areas}

A noteworthy difference was observed between the two approaches of partial outer dike removal (Fig. 8a and b). When considering propagule inflow from adjacent mangrove areas, approach 1 (northeast/north dike removal) was the most effective, as propagule concentrations within shrimp farm area $\mathrm{A}$ and $\mathrm{B}$ were much higher than those generated by approach 2 (southeast/northwest dike removal). Minimum, 
Scenario 1: 'What is the effect of species-specific buoyancy characteristics on propagule dispersal?' A) Avicennia officinalis

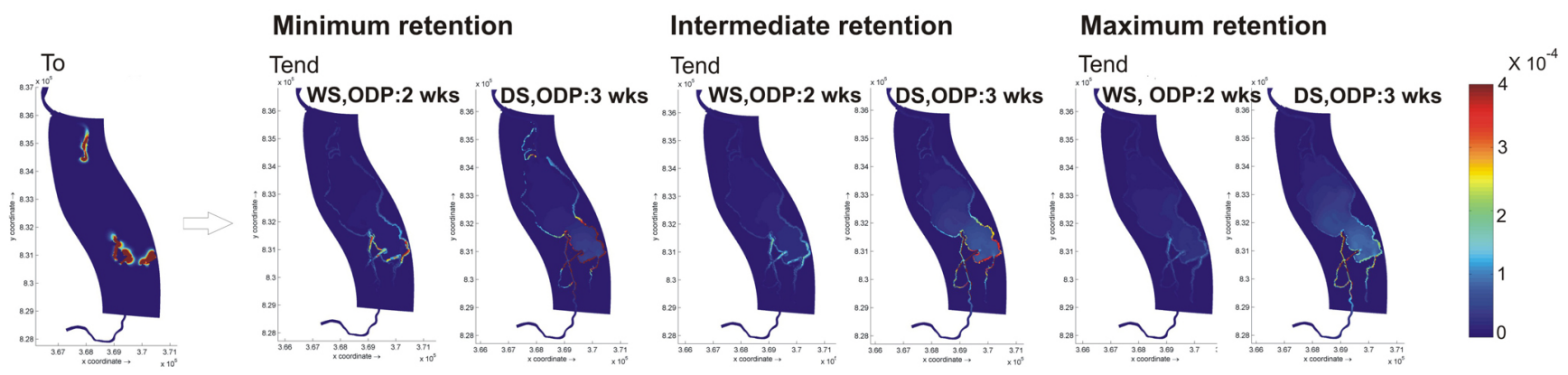

Fig. 5a. Results of scenario 1 (effect of species-specific buoyancy) showing the distribution plots of Avicennia officinalis. WS = wet season, $\mathrm{DS}=$ dry season, ODP = obligated dispersal period. Red, yellow and light blue colours indicate a high, medium and low concentration of propagules respectively.

\section{Scenario 1: 'What is the effect of species-specific buoyancy characteristics on propagule dispersal?'}

B) Ceriops tagal

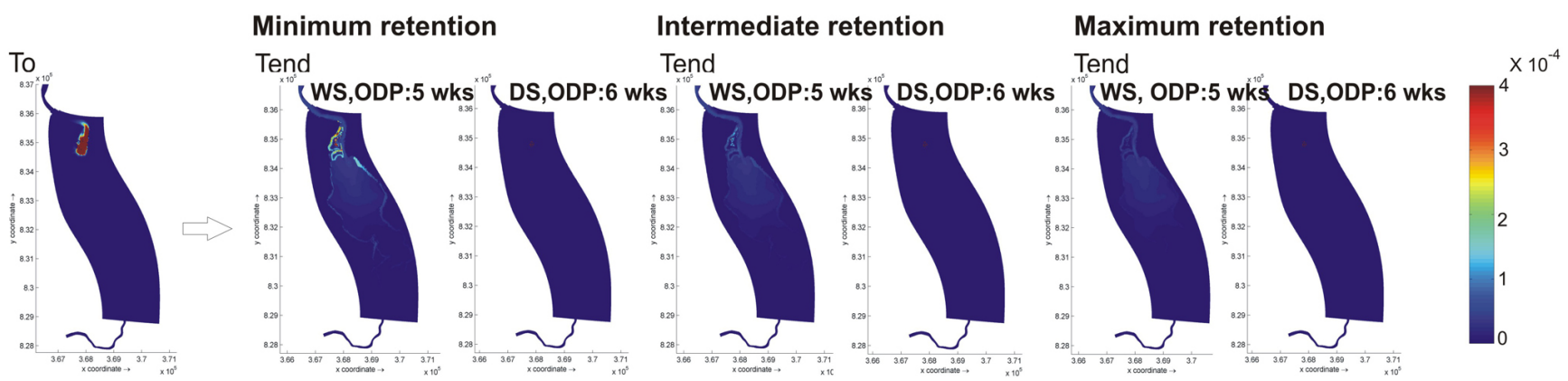

Fig. 5b. Results of scenario 1 (effect of species-specific buoyancy) showing the distribution plots of Ceriops tagal. WS = wet season, $\mathrm{DS}=$ dry season, $\mathrm{ODP}=$ obligated dispersal period. Red, yellow and light blue colours indicate a high, medium and low concentration of propagules respectively.

\section{Scenario 1: 'What is the effect of species-specific buoyancy characteristics on propagule dispersal?'}

C) Rhizophora apiculata

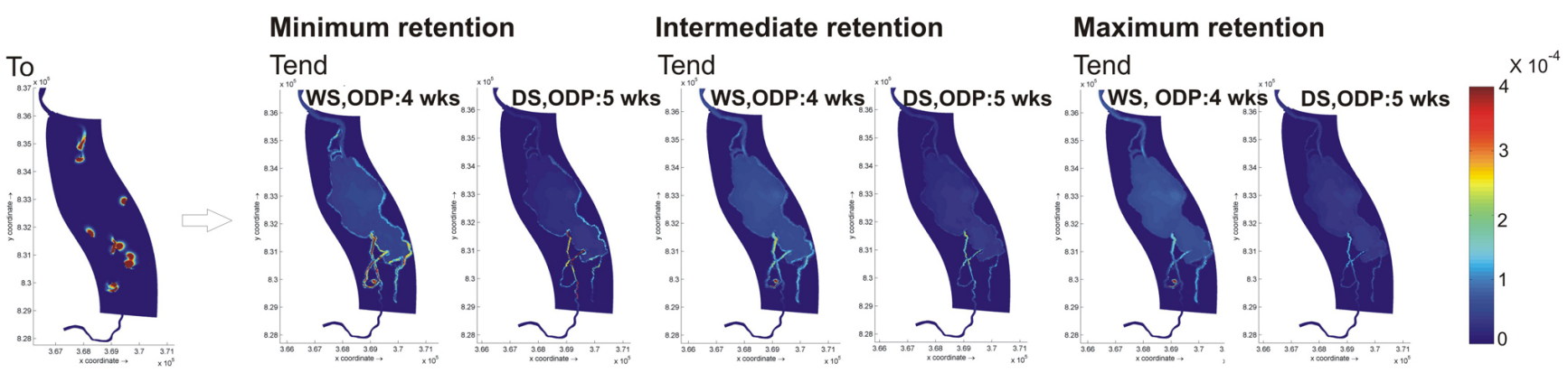

Fig. 5c. Results of scenario 1 (effect of species-specific buoyancy) showing the distribution plots of Rhizophora apiculata. WS = wet season, $\mathrm{DS}=$ dry season, ODP = obligated dispersal period. Red, yellow and light blue colours indicate a high, medium and low concentration of propagules respectively. 


\section{Scenario 2: 'What is the effect of drying of propagules on their dispersal?'}

\section{Buoyancy period of 2 weeks Intermediate retention scheme}

\section{WET SEASON}

\section{A) Rhizophora mucronata}
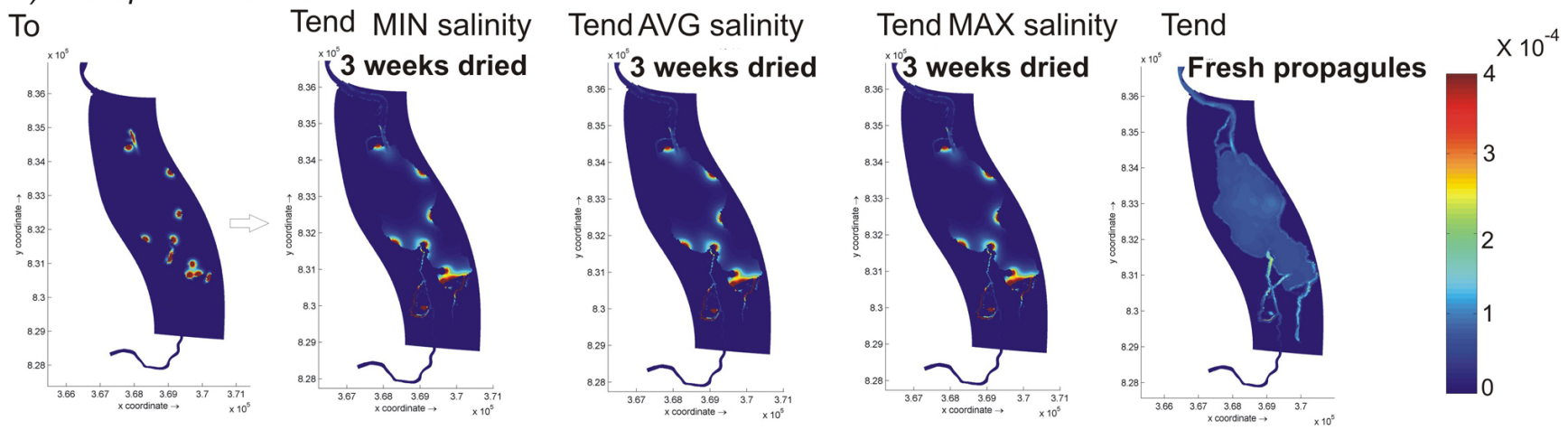

Fig. 6a. Results of scenario 2 (effect of drying) showing the distribution plots of Rhizophora mucronata in the wet season. Red, yellow and light blue colours indicate a high, medium and low concentration of propagules respectively.

\section{Scenario 2: 'What is the effect of drying of propagules on their dispersal?'}

Buoyancy period of 2 weeks Intermediate retention scheme

DRY SEASON

B) Rhizophora apiculata

To

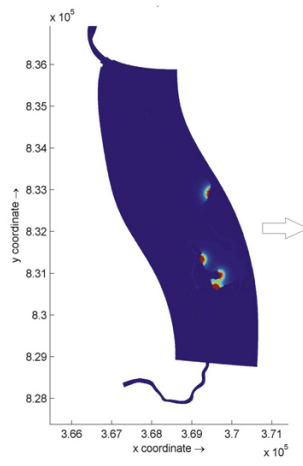

Tend MIN salinity

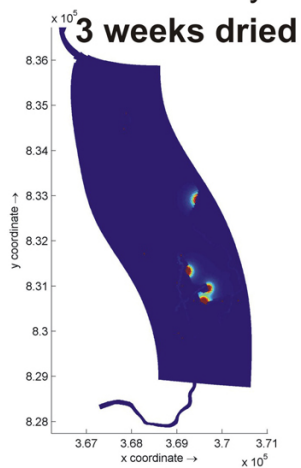

Tend AVG salinity

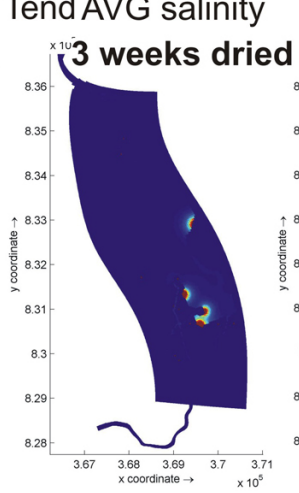

Tend MAX salinity Tend

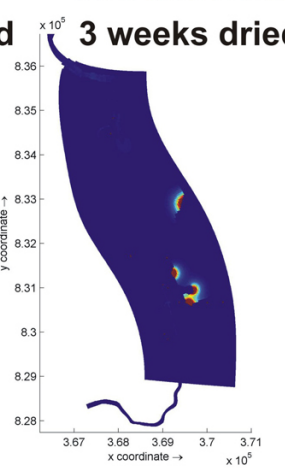

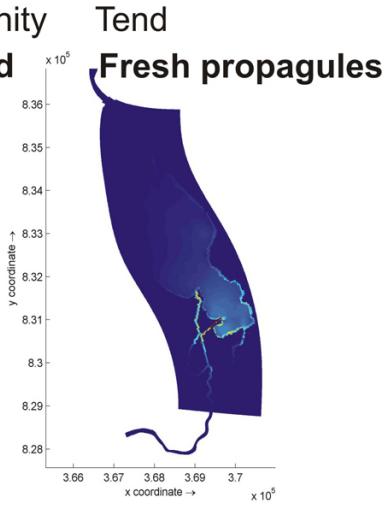

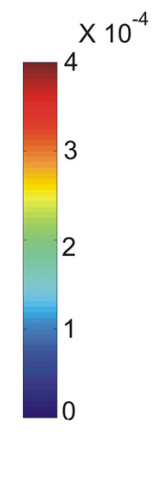

Fig. 6b. Results of scenario 2 (effect of drying) showing the distribution plots of Rhizophora apiculata in the dry season. Red, yellow and light blue colours indicate a high, medium and low concentration of propagules respectively.

intermediate and maximum retention all showed comparable distribution patterns with the same order of magnitude (results not shown). Additionally, a seasonal comparison indicated that propagule inflow in shrimp farm area A and B was most efficient during the wet season when water levels rose to guarantee flooding of these areas (Fig. 8a). Figure 8c shows the different concentrations of each species during the wet season when parts of the outer dikes were removed according to approach 1. As Ceriops tagal only occurs within the northern mangrove area, concentrations of this species were highest in shrimp farm area A, an area where Rhizophora apiculata and $R$. mucronata are also equally present. The most abundant species entering shrimp farm area B were $R$ hi- zophora apiculata and R. mucronata, yet the presence of Avicennia officinalis was not insignificant, considering the relatively low initial concentrations of propagules released in the model. The extent of the propagule inflow within shrimp farm area A reached observation point SA1, though with a lower magnitude than the inflow towards observation point SB3 in shrimp farm area B (Fig. 1). Propagule dispersal towards observation points SA6 and SA7 was obstructed due to the presence of dikes of two shrimp farms that are still active. The effect of high wind velocities played a significant additional role in the dispersal of propagules during the wet season towards the designated shrimp farm areas (results not shown). Concerning shrimp farm area A, the effect of wind 


\title{
Scenario 3: 'What is the effect of wind on propagule dispersal?'
}

\author{
WET PERIOD
}

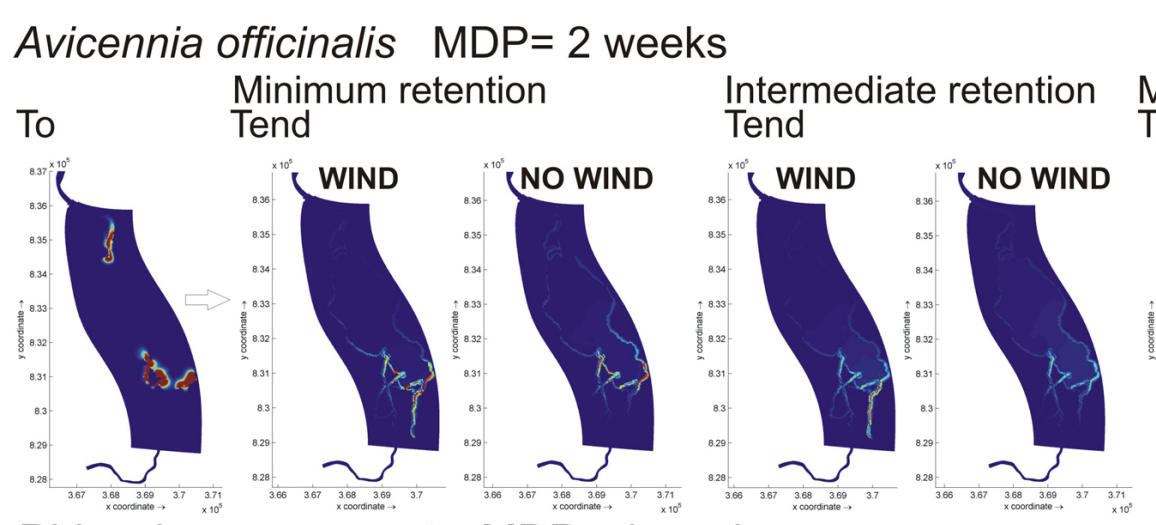
Maximum retention Tend

Rhizophora mucronata $\mathrm{MDP}=4$ weeks
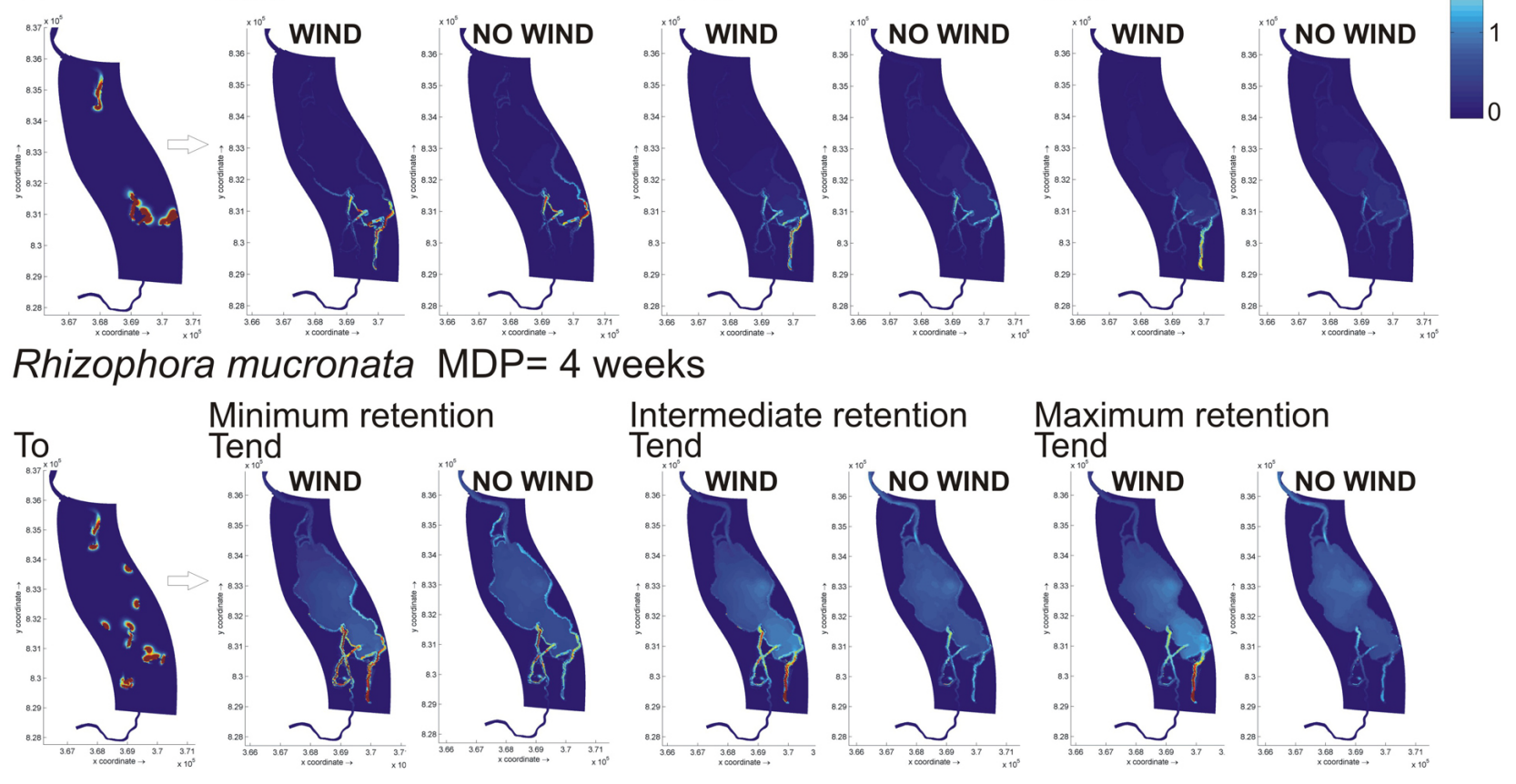

Fig. 7. Results of scenario 3 (the effect of "additional wind") showing the distribution plots of propagules of Avicennia officinalis and Rhizophora mucronata. Scale is applicable to all distribution patterns. Red, yellow and light blue colours indicate a high, medium and low concentration of propagules respectively.

was variable during the time span of propagule dispersal for all species, whereas for shrimp farm area B, higher propagule concentrations for all species were generated when "additional" wind was imposed in the model.

\section{Discussion}

\subsection{Propagule dispersal from a species perspective}

Dispersal of seeds and propagules can strongly influence the population dynamics and community structure in vegetated systems dominated by water dispersal (Honnay et al., 2001; Jansson et al., 2005; Nilsson et al., 2002). The results of the present modelling study on the dispersal of water-buoyant propagules confirm the importance of tidal flow, wind, and freshwater discharge as dispersal vectors, propagule retention by vegetation as a trapping agent and buoyancy as seed characteristic in the context of propagule distribution. The sensitivity analysis revealed that the dispersal of smaller, oval-shaped propagules is more sensitive to a variation in retention schemes and buoyancy period than the dispersion of larger, torpedo-shaped propagules. In accordance with the Tidal Sorting Hypothesis (TSH) of Rabinowitz (1978), smaller propagules were found to disperse over larger distances than larger propagules. This was mainly due to their sensitivity towards values of retention and release in combination with the location of parental trees. We do however not fully support the TSH. Like the reassessment of the latter theory by Sousa et al. (2007) indicated, propagule dispersal is not always directed towards areas more inland, but can be strongly concentrated towards the edges of lagoons and channels, as confirmed by the present study. This directional dispersal pattern is typical for areas with a small tidal range where high seasonal rainfall causes an additional flow of runoff that overwhelms any tendency for incoming tidal flow to carry propagules inland (Sousa et al., 2007). Moreover, species located along the edges of lagoons and channels, like in this case Avicennia officinalis, can drop their propagules directly into adjacent tidal creeks, allowing for dispersal over larger distances by currents if they remain buoyant. The possibility for Long Distance Dispersal (LDD) of mangrove propagules, in this study defined as 
Scenario 4: 'What is the effect of dike removal (shrimp pond rehabilitation) on propagule dispersal?'

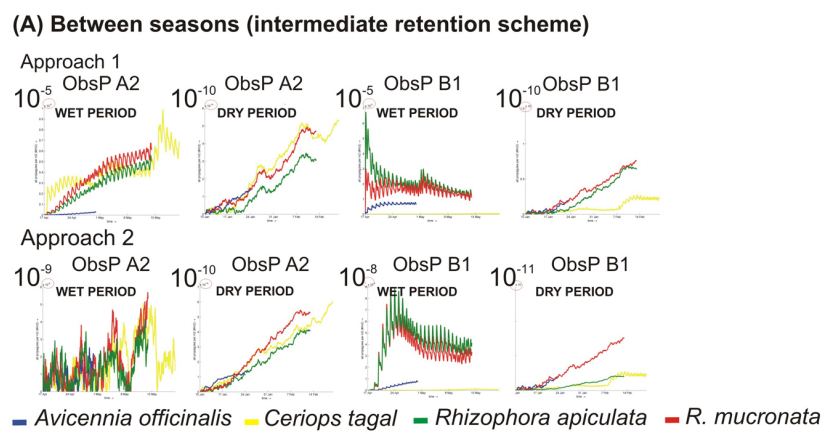

(B) Between approaches (WET season) Intermediate retention

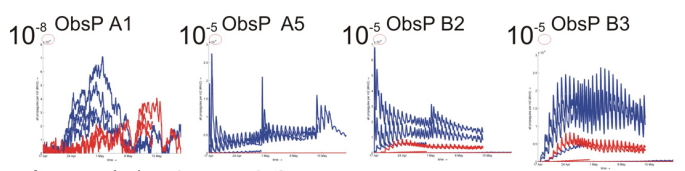

- Approach 1 - Approach 2

(C) Between species (WET season)

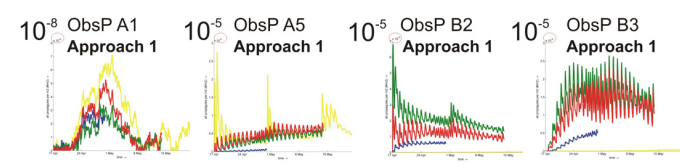

- Avicennia officinalis - Ceriops tagal = Rhizophora apiculata - R. mucronata

Fig. 8. Results of scenario 4 (the effect of dike removal) showing the time-series plots of Avicennia officinalis, Ceriops tagal and Rhizophora apiculata and Rhizophora mucronata. A comparison was made between (A) seasons (wet versus dry season), (B) approaches of outer dike removal (In approach 1, 60 m of an outer dike was removed at the northeastern side of shrimp farm A and the northern side of shrimp farm B, while in approach 2 part $60 \mathrm{~m}$ of the outer dike at the southeastern side of shrimp farm A and the northwestern side of shrimp farm B was removed) and (C) the different species. ObsP Ax = observation point in shrimp farm area $\mathrm{A}$, ObsP $\mathrm{Bx}=$ observation point in shrimp farm area $\mathrm{B}$. X-axes = buoyancy period (days), $\mathrm{y}$-axes $=$ propagule density $\mathrm{m}^{-2}$.

the movement of propagules leaving the system, has been acknowledged by many authors (Clarke, 1993; Sauer, 1988; Sengupta et al., 2005; Stieglitz and Ridd, 2001). As an example, Clarke (1993) discovered that during one single flood tide propagules of Avicennia marina could disperse as far as $500 \mathrm{~m}$ from their release point along tidal creeks that enter Jervis Bay (Australia). Within the Pambala-Chilaw Lagoon complex, it appeared that hydrodynamics allows for only a small part of the propagules (max. $5 \%$ for each species) to leave the system via the northern part of the Dutch Canal. Few propagules of $R$. apiculata and $R$. mucronata were indeed found along the northern sea mouth, strangled within a pile of waste along the sides of the channel (personal observation). However, Short Distance Dispersal (SDD) appeared to be the main dispersal strategy for all four concerned species in this modelling exercise. The majority of propagules remained within the lagoon and its adjacent channels, and often near the parental trees. Field experiments support these findings as modal or average propagule movement of Rhizophora and even Avicennia was found to be limited and concentrated near the parental trees, especially within mature forest stands (Clarke and Myerscough, 1993; De Ryck, 2009; McGuinness, 1997; Sousa et al., 2007). Water-buoyant propagules may set out to colonise and establish new stands but like in most plant species, they will rather strand in the vicinity of the parent trees to replenish existing stands (Duke et al., 1998; Harper, 1977; Levin et al., 2003; Sousa et al., 2007) with a higher chance of suitable environmental conditions. Stranding and self-planting are known dispersal strategies of the family Rhizophoraceae (Van Speybroeck, 1992). Stranding of these propagules does not per se imply long distance dispersal, as dispersion can occur in the vicinity of the parental mangrove trees. Self-planting on the other hand entails that a propagule falls from the parental tree with the possibility to self-plant underneath. Nevertheless, questions concerning the ecological advantage of long distance versus short distance dispersal arise. As the sensitivity analysis showed, propagules of a typical pioneer species Avicennia officinalis, could reach areas further afield if their obligated dispersal period (ODP), more specifically the time taken for viable propagules to start developing lateral roots, would exceed $2 / 3$ weeks. The ODP of $R$. apiculata and $R$. mucronata provides chances for colonisation of new areas, yet LDD of these species is inhibited by retention within the vegetation. Furthermore, the effect of drying of propagules, especially in areas with a small tidal range, concentrates propagule distribution near their release points and can further inhibit LDD. Longevity, the period required for establishment and the period of obligated dispersal are therefore vital factors to determine the ability of propagules to survive dispersal both locally and across large expanses of ocean (Drexler, 2001). A comparison between Rhizophora spp. species by Drexler (2001) pointed out that Rhizophora mucronata propagules are better equipped for LDD, yet have lower rate of survival concerning establishment than propagules of $R$. apiculata, which in their turn have a shorter longevity.

Few studies on the hydrochory of propagules have addressed the effect of wind on dispersal patterns. Results of the present study indicate that, irrespective of the retention scheme, wind can have a significant influence on their dispersal distance and direction once propagules enter the lagoon or adjacent channels. The effect of wind on propagule dispersal was generalised for all concerned species in the present study. However, differences in size, weight and shape may further alter wind-induced dispersal patterns of the different species. The effect of wave action on propagule dispersal, which was not included in this study, also deserves attention in future studies.

Although this pioneer modelling exercise showed promising results with respect to propagule dispersal processes, it is still in its early stages. We therefore emphasise the importance of additional field experiments to quantify the dispersal 
distances and directions of each species in different environmental settings (see Sousa et al., 2007), as well as propagule retention by vegetation (see Chang et al., 2008).

\subsection{Implications of propagule dispersal for shrimp pond rehabilitation}

Tidal flooding regime and propagule availability are key issues when restoring mangroves in abandoned shrimp pond areas (Lewis III, 2005). Our results indicate that, irrespective to the retention schemes, a computer-based ecological engineering project can provide valuable information on the most suitable locations of propagule inflow (approach 1) through simulating the removal of parts of outer pond dikes. Inflow of propagules of different species clearly depends on the location of dike removal, suitable hydrodynamic flows and on the presence of these particular species in adjacent mangrove stands. The latter was shown in this study for Ceriops tagal, which appeared more likely to colonise abandoned shrimp farm areas in the northern part of the Chilaw lagoon. Given the extent of this species present distribution within the lagoon and its inner mangrove character, propagule dispersal to abandoned shrimp farm areas in southern parts is limited. Wind velocity played an additional role influencing the dispersal of propagules towards the designated shrimp farm areas.

Favourable dispersal patterns alone do not guarantee successful establishment and persistence of these species within the disused shrimp farms. Prior to seedling establishment, processes such as dispersal towards the concerning shrimp farm areas and propagule predation are likely to influence initial patterns of distribution and abundance (Cannicci et al., 2008; Dahdouh-Guebas et al., 1997, 1998; McGuinness, 1994; McKee, 1995; Osborne and Smith, 1990). Once arrived in the abandoned shrimp farms, other factors like physico-chemical characteristics of the sediment (Delgado et al., 2001), predation (Cannicci et al., 2008), acid sulphate soils (Sammut and Hanafi, 2000), interspecific competition and frequency of inundation (Kitaya et al., 2002) may further affect the success of establishment, early growth and survival of seedlings and ultimately determine the success of natural regeneration.

Several researchers have recently focused on the potential role of mangroves as purifiers of effluents and sediment derived from shrimp aquaculture ponds (Costanzo et al., 2004; Jackson et al., 2003; Shimoda et al., 2005), but research results concerning seedling growth and interspecific competition within abandoned ponds are scarce. Rajendran and Katherisan (1996) studied the effect of effluent from a shrimp pond on growth in terms of shoot dry weight of 5 mangrove species (Avicennia marina (Forsk.) Vierh., A. officinalis, Ceriops decandra (Griff.) Ding Hou, Rhizophora mucronata and $R$. apiculata). Raw effluents had a negative effect on the shoot dry weight of the species $R$. apiculata and C. decandra while effluents diluted by $70 \%$ improved the shoot biomass production of all mangrove seedlings. General studies concerning the effects of soil moisture, salinity and sediment accretion on propagule establishment could give more insights on the potential for natural regeneration within abandoned shrimp farms at Pambala-Chilaw Lagoon. Desiccated soils within these shrimp farms may prove to be unsuitable for propagule establishment and in addition, possible sediment accretion during flooding may cause further stresses. Survival of planted propagules of Ceriops tagal was found to be correlated with soil moisture and salinity and was lower in cleared areas than in small light gaps within a north Australian mangrove (McGuinness, 1997). Mortality of $R$. apiculata seedlings was found to be closely related to soil hardness (Komiyama et al., 1998). These findings suggest that the indirect effects of light on soil conditions may be more critical than its direct effects on the plants themselves. Rhizophora apiculata seedlings appear to be inefficient colonisers of coastal areas exposed to sudden events of high $(>4 \mathrm{~cm})$ sediment accretion (Terrados et al., 1997; Thampanya et al., 2002). Furthermore, competition with non-mangrove species could pose an additional limiting factor for mangrove regeneration in the abandoned shrimp farms, unless they function as a trap for propagule recruitment.

Despite these constraints, we have in situ observed some degree of natural regeneration within a few abandoned ponds of shrimp farm area B in favour of Rhizophora spp. Case studies elsewhere (southern Thailand) also indicate that the potential exists for converting abandoned shrimp ponds areas back to mangroves within a period of about 5 to $10 \mathrm{yr}$ provided that there is sufficient recruitment of viable propagules and hydrological conditions are restored (Lewis III et al., 2002). After performing the ecological engineering project in the field; we do however suggest future monitoring of the natural mangrove regeneration to check whether or not natural recruitment provides the quantity of successfully established seedlings, rate of stabilisation or rate of sapling growth required to meet the objectives and expectations of the mangrove restoration project. In case of insufficient results, Assisted Natural Regeneration (ANR) can be opted using the harvest and transplantation of excess wildings which have proven to return a 9 ha pond into mangroves in only $4 \mathrm{yr}$, with some of the wildings flowering in just $3 \mathrm{yr}$ after transplantation (Primavera et al., 2012b). The Pambala-Chilaw Lagoon Complex and other mangrove areas in Sri Lanka have been researched by our scientific laboratories for the past decennia (e.g. Dahdouh-Guebas et al., 2011,, 2002a; Verheyden et al., 2002) so that information on densities of wild recruits in the present study and within different biotic and abiotic settings are available. Furthermore, a mangrove rehabilitation project by the Small Fishers Federation of Lanka led to the planting of about 50000 mangrove seedlings in Pambala Lagoon in an area inland, close to the shrimp farm areas. The reforestation plots covering around 2.4 ha are often visited in the field and vital information for future projects is gathered. 
While seed ecology is a well-developed field, the understanding of processes driving propagule dispersal has not been advancing. On the contrary, it remained stuck in speculation even in spite of its importance towards socially and ecologically induced pond abandonment. Studies on mangrove ecology indicate that a wide variety of factors, including propagule buoyancy, tolerance to salinity, desiccation, disturbance, stochastic events, competition and predation, may affect the distribution and abundance of species. Regarding mangrove establishment, there are however few studies that examine the relative importance of these different factors for individual species, but also for the interaction between these species in different environmental settings. Pond restoration projects therefore require insight on both propagule dispersal towards and establishment within "stressful" areas, or knowledge on means to pro-actively diminish these stresses in order to stimulate natural regeneration.

Acknowledgements. We thank the people of the Small Fishers Federation Lanka, especially Chamara Jayasooriya for his assistance in the field. Many thanks are also due to Dr. Wijeratne from the National Aquatic Resources Research and Development Agency in Colombo (Sri Lanka) for providing the water level measurements and to Firmijn Zijl from Deltares for his guidance during the set-up of the hydrodynamic model. This research was funded by the Flemish Interuniversity Council (VLIR), the Fonds David \& Alice Van Buuren and D. Di Nitto has a VLIR PhD Scholarship. This work was in part presented at the International Interdisciplinary Conference "Hydropredict 2008" (20-24 September, Czech Republic, Prague) and in part at the Meeting on Mangrove ecology, functioning and Management - MMM3 (2-6 July 2012, Sri Lanka, Galle).

Edited by: B. Satyanarayana

\section{References}

Alongi, D. M.: Mangrove forests: Resilience, protection from tsunamis, and responses to global climate change, Estuar. Coast. Shelf S., 76, 1-13, 2008.

Baranasuriya, P. W.: Hydrographic investigations for the design of an anchorage in a complex lagoon estuary, A Spatial Odyssey: 42nd Australian Surveyors Congress, 2001.

Beveridge, M. C. M., Phillips, M. J., and Macintosh, D. J.: Aquaculture and the environment: the supply of and demand for environmental goods and services by Asian aquaculture and the implications for sustainability, Aquac. Res., 28, 797-807, 1997.

Bosire, J. O., Dahdouh-Guebas, F., Walton, M., Crona, B. I., Lewis, R. R., Field, C., Kairo, J. G., and Koedam, N.: Functionality of restored mangroves: A review, Aquat. Bot., 89, 251-259, 2008.

Cannicci, S., Burrows, D., Fratini, S., Smith, T. J., Offenberg, J., and Dahdouh-Guebas, F.: Faunal impact on vegetation structure and ecosystem function in mangrove forests: A review, Aquat. Bot., 89, 186-200, 2008.

Chang, E. R., Veeneklaas, R. M., Buitenwerf, R., Bakker, J. P., and Bouma, T. J.: To move or not to move: determinants of seed retention in a tidal marsh, Funct. Ecol., 22, 720-727, 2008.
Clarke, P. J.: Dispersal of grey mangrove (Avicennia marina) propagules in Southeastern Australia, Aquat. Bot., 45, 195-204, 1993.

Clarke, P. J. and Myerscough, P. J.: The intertidal distribution of the grey mangrove (Avicennia marina) in southeastern Australia: the effects of physical conditions, interspecific competition, and predation on propagule establishment and survival, Aust. J. Ecol., 18, 307-315, 1993.

Clarke, P. J., Kerrigan, R. A., and Westphal, C. J.: Dispersal potential and early growth in 14 tropical mangroves: do early life history traits correlate with patterns of adult distribution?, J. Ecol., 89, 648-659, 2001.

Costanzo, S. D., O’Donohue, M. J., and Dennison, W. C.: Assessing the influence and distribution of shrimp pond effluent in a tidal mangrove creek in north-east Australia, Mar. Pollut. Bull., 48, 514-525, 2004.

Dahdouh-Guebas, F., Verneirt, M., Tack, J. F., and Koedam, N.: Food preferences of Neosarmatium meinerti de Man (Decapoda: Sesarminae) and its possible effect on the regeneration of mangroves, Hydrobiologia, 347, 83-89, 1997.

Dahdouh-Guebas, F., Verneirt, M., Tack, J. F., Van Speybroeck, D., and Koedam, N.: Propagule predators in Kenyan mangroves and their possible effect on regeneration, Mar. Freshwater Res., 49, 345-350, 1998.

Dahdouh-Guebas, F., Verheyden, A., De Genst, W., Hettiarachchi, S., and Koedam, N.: Four decade vegetation dynamics in Sri Lankan mangroves as detected from sequential aerial photography: A case study in Galle, B. Mar. Sci., 67, 741-759, 2000.

Dahdouh-Guebas, F., Kairo, J. G., Jayatissa, L. P., Cannicci, S., and Koedam, N.: An ordination study to view vegetation structure dynamics in disturbed and undisturbed mangrove forests in Kenya and Sri Lanka, Plant Ecol., 161, 123-135, 2002a.

Dahdouh-Guebas, F., Zetterström, T., Rönnbäck, P., Troell, M., Wickramasinghe, A., and Koedam, N.: Recent changes in landuse in the Pambala-Chilaw Lagoon complex (Sri Lanka) investigated using remote sensing and GIS : conservation of mangroves vs. development of shrimp farming, Environment, Development and Sustainability, 4, 185-200, 2002b.

Dahdouh-Guebas, F., Jayatissa, L. P., Di Nitto, D., Bosire, J. O., Lo Seen, D., and Koedam, N.: How effective were mangroves as a defence against the recent tsunami?, Curr. Biol., 15, 1337-1338, 2005.

Dahdouh-Guebas, F., Koedam, N., Satyanarayana, B., and Cannicci S.: Human hydrographical changes interact with propagule predation behaviour in Sri Lankan mangrove forests, J. Exp. Mar. Biol. Ecol., 399, 188-200, 2011.

Delgado, P., Hensel, P. F., Jimenez, J. A., and Day, J. W.: The importance of propagule establishment and physical factors in mangrove distributional patterns in a Costa Rican estuary, Aquat. Bot., 71, 157-178, 2001.

De Ryck, D.: Moving and settling: Experiments on the dispersal and establishment of hydrochorous propagules, Master Thesis, Vrije Universiteit Brussel, Brussels, 2009.

De Silva, R. I. and Jacobson, S.: Mundel Lake (Sri Lanka): An important habitat for migratory shorebirds. Published by the Wlidlife and Nature Protection Society of Sri Lanka, 1995.

Domroes, M. and Ranatunge, E.: The orthogonal structure of Monsoon rainfall variation over Sri Lanka, Theor. Appl. Climatol., 46, 109-114, 1992. 
Drexler, J. Z.: Maximum longevities of Rhizophora apiculata and R. mucronata propagules, Pac. Sci. 55, 17-22, 2001.

Duke, N. C., Ball, M. C., and Ellison, J. C.: Factors influencing biodiversity and distributional gradients in mangroves, Global Ecol. Biogeogr., 7, 27-47, 1998.

Erftemeijer, P. L. A., van Beek, J. K. L., Ochieng, C. A., Jager, Z., and Los, H. J.: Eelgrass seed dispersal via floating generative shoots in the Dutch Wadden Sea: a model approach, Mar. Ecol.Prog. Ser., 358, 115-124, 2008.

FAO Inland Water Resources and Aquaculture Service: Review of the state of world aquaculture, FAO Fisheries Circular, No. 886, Rev. 2, Rome, FAO, 95p., 2003.

Foell, J., Harrison, E., and Stirrat, R. L.: Participatory approaches to natural resource management - the case of coastal zone management in the Puttalam District, Summary findings of DFID-funded research "participatory mechanisms for sustainable development of coastal ecosystems" (Project R6977), School of African and Asian studies, Falmer, Brighton, UK, University of Sussex, 1999.

Gilman, E. L., Ellison, J., Duke, N. C., and Field, C.: Threats to mangroves from climate change and adaptation options: A review, Aquat. Bot., 89, 237-250, 2008.

Harper, J. L.: Population Biology of Plants. Academic Press, London, 1977.

Higazi, L.: De verspreiding en vestiging van mangrove-propagulen in het micro-getijdengebied Pambala-Chilaw Lagune (Sri Lanka) - een experimentele aanpak, MSc. thesis, Vrije Universiteit Brussel, Brussels, 2008.

Honnay. O., Verhaeghe, W., and Hermy, M.: Plant community assembly along dendritic networks of small forest streams, Ecology and Freshwater Fish, 82, 1691-1702, 2001.

Jackson, C. J., Preston, N., Burford, M. A., and Thompson, P. J.: Managing the development of sustainable shrimp farming in Australia: the role of sedimentation ponds in treatment of farm discharge water, Aquaculture, 226, 23-34, 2003.

Jansson, R., Zinko, U., Merritt, D. M., and Nilsson, C.: Hydrochory increases riparian plant species richness: a comparison between a free-flowing and a regulated river, J. Ecol., 93, 1094-1103, 2005.

Jayasinghe, J. M. P. K.: Sri Lanka, 357-376. FAO/NACA 1995, Regional Study and Workshop on the Environmental Assessment and Management of Aquaculture Development (TCPIRAS12253). Bangkok, Thailand: NACA Environment and Aquaculture Development Series No. I. Network of Aquaculture Centres in Asia-Pacific, 1995.

Jayatissa, L. P., Dahdouh-Guebas, F., and Koedam, N.: A review of the floral composition and distribution of mangroves in Sri Lanka, Bot. J. Linn, Soc., 138, 29-43, 2002.

Jolliff, J. K., Kindle, J. C., Shulman, I., Penta, B., Friedrichs, M. A. M., Helber, R., and Arnone, R. A.: Summary diagrams for coupled hydrodynamic-ecosystem model skill assessment, J. Marine Syst., 76, 64-82, 2009.

Kautsky, N., Ronnback, P., Tedengren, M., and Troell, M.: Ecosystem perspectives on management of disease in shrimp pond farming, Aquaculture, 191, 145-161, 2000.

Kitaya, Y., Jintana, V., Piriyayotha, S., Jaijing, D., Yabuki, K., Izutani, S., Nishimiya, A., and Iwasaki, M.: Early growth of seven mangrove species planted at different elevations in a Thai estuary, Trees-Struct. Funct., 16, 150-154, 2002.

Komiyama, A., Tanapermpool, P., Havanond, S., Maknual, C., Patanaponpaiboon, P., Sumida, A., Ohnishi, T., and Kato, S.:
Mortality and growth of cut pieces of viviparous mangrove ( $R h$ izophora apiculata and $R$. mucronata) seedlings in the field condition, Forest Ecol. Manag., 112, 227-231, 1998.

Kumara, G. W. N. T.: A study of some biological aspects pertaining to conservation and sustainable use of Rhizophoraceae mangroves in Sri Lanka with particular emphasis on phenology, Msc. Thesis, University of Ruhuna, Sri Lanka, 2001.

Launder, B. E. and Spalding, D. B.: Mathematical Models of Turbulence. New York: Academic Press, 1982.

Leendertse, J. J.: A three-dimensional alternating direction implicit model with iterative fourth order dissipative non-linear advection terms WD-3333-NETH, Rijkswaterstaat, 1987.

Lesser, G. R., Roelvink, J. A., Van Kester, J. A. T. M., and Stelling, G. S.: Development and validation of a three-dimensional morphological model, Coast. Eng., 51, 883-915, 2004.

Levin, S. A., Muller-Landau, H. C., Nathan, R., and Chave, J.: The ecology and evolution of seed dispersal: a theoretical perspective, Annu. Rev. Ecol. Evol. S., 34, 575-604, 2003.

Lewis III, R. R.: Key concepts in successful ecological restoration of mangrove forests, 12-32, in: Proceedings of the TCEWorkshop No. II, Coastal Environmental Improvement in Mangrove/Wetland Ecosystems, 18-23 August 1998, Ranong, Thailand, Danish-SE Asian Collaboration in Tropical Coastal Ecosystems (TCE) Research and Training. NACA, P.O. Box 1040, Bangkok, Thailand 10903, 1999.

Lewis III, R. R.: Ecological engineering for successful management and restoration of mangrove forests, Ecol. Eng., 24, 403-418, 2005.

Lewis III, R. R. and Marshall, M. J.: Principles of successful restoration of shrimp aquaculture ponds back to mangrove forests. Page 327 in World Aquaculture Society Book of Abstracts, Aquaculture '98, Las Vegas, Nevada, (Abstract), 1998.

Lewis III, R. R., Erftemeijer, P. L. A., Sayaka, A., and Kethkaew, P.: Mangrove rehabilitation after shrimp aquaculture: A case study in progress at the Don Sak National Forest Reserve, Surat Thani, Southern Thailand, Case Study 13, in: Annexes to the Thematic Review on Coastal Wetland Habitats and Shrimp Aquaculture, edited by: Macintosh, D. J., Phillips, M. J., Lewis III, R. R., and Clough, B., Case Studies 7-13, Report prepared under the World Bank, NACA, WWF and FAO Consortium Program on Shrimp Farming and the Environment, 108-128, 2002.

Lewis III, R. R., Phillips, M. J., Clough, B., and Macintosh, D. J.: Thematic Review on Coastal Wetland Habitats and Shrimp Aquaculture. Report prepared under the World Bank, NACA, WWF and FAO Consortium Program on Shrimp Farming and the Environment, Work in Progress for Public Discussion, Published by the Consortium, 81 pp., 2003.

Lewis III, R. R., Quarto, A., Enright, J., Corets, E., Primavera, J., Ravishankar, T., Stanley, O. D., and Djamaluddin, R.: Five Steps to Successful Ecological Restoration of Mangroves. YARL and the Mangrove Action Project, Yogyakarta, Indonesia, 64 pp., Report no., 2006.

Lugo, A. E. and Snedaker, S. C.: The ecology of mangroves, Annu. Rev. Ecol. Syst., 5, 39-64, 1974.

McGuinness, K. A.: The climbing behaviour of Cerithidea anticipata (Mollusca: Gastropoda): the roles of physical and biological factors, Aust. J. Ecol., 19, 283-289, 1994.

McGuinness, K. A.: Dispersal, establishment and survival of Ceriops tagal propagules in a north Australian mangrove forest, Oe- 
cologia, 109, 80-87, 1997.

McKee, K. L.: Seedling recruitment patterns in a Belizean mangrove forest - Effects of establishment ability and physicochemical Factors, Oecologia, 101, 448-460, 1995.

Mueller-Dombois, D.: Ecogeographic analysis of a climate map of Ceylon with particular reference to vegetation. Including climate diagram map of Ceylon at 1:506,880, The Ceylon Forester, 8, 39-58, 1968.

Naylor, R. L., Goldburg, R. J., Primavera, J. H., Kautsky, N., Beveridge, M. C. M., Clay, J., Folke, C., Lubchenco, J., Mooney, H., and Troell, M.: Effect of aquaculture on world fish supplies, Nature, 405, 1017-1024, 2000.

Nilsson, C., Andersson, E., Merritt, D. M., and Johansson, M. E.: Differences in riparian flora between riverbanks and river lakeshores explained by dispersal traits, Ecology and Freshwater Fish, 83, 2878-2887, 2002.

Osborne, K. and Smith, T. J. I.: Differential predation on mangrove propagules in open and closed canopy forest habitats, Vegetatio, 89, 1-6, 1990.

Patil, P. G. and Krishan, M.: The Kandaleru shrimp farming industry and its impact on the rural economy, Agricultural Economics Research Review, 10, 293-308, 1997.

Postma, L.: DELWAQ Users manual, Version 3.0: WL |Delft Hydraulics, 1988.

Primavera, J. H.: A critical review of shrimp pond culture in the Philippines, Rev. Fish. Sci., 1, 151-201, 1988.

Primavera, J. H.: Intensive prawn farming in the Philippines: Ecological, social and economic implications, Ambio, 20, 28-33, 1991.

Primavera, J. H.: A critical Review of Shrimp Pond Culture in the Philippines, Rev. Fish. Sci., 1, 151-201, 1993.

Primavera, J. H.: Mangroves as nurseries: Shrimp populations in mangrove and non-mangrove habitats, Estuar. Coast. Shelf S., 46, 457-464, 1998.

Primavera, J. H., Rollon, R. N., and Samson, M. S.: The Pressing Challenges of Mangrove Rehabilitation: Pond Reversion and Coastal Protection, Chapter 10 in Volume 10, in: Ecohydrology and restoration in the Treatise on Estuarine and Coastal Science, edited by: Chicharo, L. and Zalewski, M., 217-244, Amsterdam, Elsevier, 2012a.

Primavera, J. H., Savaris, J. P., Bajoyo, B. E., Coching, J. D., Curnick, D. J., Golbeque, R. L., Guzman, A. T., Henderin, J. Q., Joven, R. V., Loma, R. A., and Koldewey, H. J.: Manual for community-based mangrove rehabilitation, London, Zoological Society of London, Mangrove Manual Series No. 1, 240 pp., 2012b.

Quisthoudt, K.: Mangrove en garnalenkweek in de Lagune van Chilaw (Sri Lanka): Toestand en perspectieven verlaten garnaalkwekerijenVrije Universiteit Brussel, Brussels, Belgium, 2007.

Rabinowitz, D.: Dispersal properties of mangrove propagules, Biotropica, 47-57, 1978.

Rajendran, N. and Kathiresan, K.: Effect of effluent from a shrimp pond on shoot biomass of mangrove seedlings, Aquac. Res., 27, 745-757, 1996.

Raper, J.: Three-dimensional Applications in Geographical Information Systems. London, UK, Taylor \& Francis, 1990.

Roelvink, J. A. and Van Banning, G. K. F. M.: Design and development of DELFT3D and application to coastal morphodynamics, Proc. Hydroinformatics 1994, Verwey, Minns, 1994.
Rönnbäck, P.: The ecological basis for economic value of seafood production supported by mangrove ecosystems, Ecol. Econ., 29, 235-252, 1999.

Ronnbäck, P.: Shrimp aquaculture. State of the art. Swedish International Development Agency (SIDA), Stockholm \& Swedish EIA Centre, Swedish University of Agricultural Sciences (SLU), 2001.

Rönnbäck, P., Bryceson, I., and Kautsky, N.: Coastal Aquaculture development in eastern Africa and the Western Indian Ocean: Prospects and problems for food security and local economies, Ambio, 31, 537-542, 2002.

Rönnbäck, P., Troell, M., Zetterstrom, T., and Babu, D. E.: Mangrove dependence and socio-economic concerns in shrimp hatcheries of Andhra Pradesh, India, Environ. Conserv., 30, 344 352, 2003.

Sammut, J. and Hanafi, A.: Remediation and Management of Shrimp Ponds Excavated in Acid Sulphate Soils. Section in Report to World Bank, FAO, NACA and WWF, Bangkok, Thailand, 2000.

Sauer, J. D.: Plant migration: The dynamics of geographic patterning in seed plant species, Berkeley, University of California Press, 1988.

Sengupta, R., Middleton, B., Yan, C., Zuro, M., and Hartman, H.: Landscape characteristics of Rhizophora mangle forests and propagule deposition in coastal environments of Florida (USA), Landscape Ecol., 20, 63-72, 2005.

Shimoda, T., Srithong, C., and Aryuthaka, C.: Attempt at purification of effluent and sediment in shrimp aquaculture ponds using mangrove trees, Jarq-Jn. Agr. Res. Q., 39, 139-145, 2005.

Sousa, W. P., Kennedy, P. G., Mitchell, B. J., and Ordonez, B. M.: Supply-side ecology in mangroves: Do propagule dispersal and seedling establishment explain forest structure?, Ecol. Monogr., 77, 53-76, 2007.

Stelling, G. S.: On the construction of computational methods for shallow water flow problems, $\mathrm{PhD}$ thesis, Delft University of Technology, Delft, the Netherlands, 1983.

Stelling, G. S. and Van Kester, T. J. A.: On the approximation of horizontal gradients in sigma coordinates for bathymetry with steep bottom slopes, Int. J. Numer. Meth. Fl., 18, 915-935, 1994.

Stevenson, N. J. and Burbridge, P. R.: Abandoned Shrimp Ponds: Options for Mangrove Rehabilitation, International Newsletter of Coastal Management, Special Edition 1, 1997.

Stevenson, N. J., Lewis, R. R., and Burbridge, P. R.: Disused Shrimp Ponds and Mangrove Rehabilitation, in: An International Perspective on Wetland Rehabilitation, edited by: Streever W., 277297, 1999.

Stieglitz, T. and Ridd, P. V.: Trapping of mangrove propagules due to density-driven secondary circulation in the Normanby River estuary, NE Australia, Mar. Ecol.-Prog. Ser., 211, 131-142, 2001.

Swan B.: An Introduction to the Coastal Geomorphology of Sri Lanka, Colombo, UNESCO, 1983.

Terrados, J., Thampanya, U., Srichai, N., Kheowvongsri, P., GeertzHansen, O., Boromthanarath, S., Panapitukkul, N., and Duarte, C. M.: The effect of increased sediment accretion on the survival and growth of Rhizophora apiculata seedlings, Estuar. Coast. Shelf S., 45, 697-701, 1997.

Thampanya, U., Vermaat, J. E., and Terrados, J.: The effect of increasing sediment accretion on the seedlings of three common 
Thai mangrove species, Aquat. Bot., 74, 315-325, 2002.

Tsanis, I. K.: Simulation of wind-induced water currents, J. Hydraul. Eng.-ASCE, 115, 1113-1134, 1989.

UNEP/GPA.: Study on Better Practices for Shrimp Farming in Chilaw and Puttlam districts of Sri Lanka. Study prepared by Small Fishers Federation, Sri Lanka. Report no., 2003.

Van Speybroeck, D.: Regeneration strategy of mangroves along the Kenya coast: a first approach, Hydrobiologia, 247, 243-251, 1992.

Verheyden, A., Dahdouh-Guebas, F., Thomaes, K., De Genst, W., Hettiarachchi, S., and Koedam, N.: High-Resolution vegetation data for mangrove research as obtained from aerial photography, Environment, Development and Sustainability, 4, 113-133, 2002.
Walters, B. B.: People and mangroves in the Philippines: fifty years of coastal environmental change, Environ. Conserv., 30, 293 303, 2003.

Walters, B. B.: Local management of mangrove forests in the Philippines: successful conservation or efficient resource exploitation?, Hum. Ecol. 32, 177-195, 2004.

Woodroffe, C. D. and Grime D.: Storm impact and evolution of a mangrove-fringed chenier plain, Shoal Bay, Darwin, Australia, Mar. Geol. 159, 303-321, 1999.

Zhang, Z. and Chen Q.: Comparison of the eulerian and lagrangian methods for predicting particle transport in enclosed spaces, Atmos. Environ., 41, 5236-5248, 2007. 